University of South Carolina

Scholar Commons

6-1993

\title{
An Exploration of High-Risk Leisure Consumption Through Skydiving
}

Richard L. Celsi

Randall L. Rose

University of South Carolina - Columbia, roser@moore.sc.edu

Thomas W. Leigh

Follow this and additional works at: https://scholarcommons.sc.edu/mark_facpub

Part of the Marketing Commons

Publication Info

Journal of Consumer Research, Volume 20, Issue 1, 1993, pages 1-23.

http://jcr.wisc.edu/

(c) 1993 by Journal of Consumer Research, Inc.

This Article is brought to you by the Marketing Department at Scholar Commons. It has been accepted for inclusion in Faculty Publications by an authorized administrator of Scholar Commons. For more information, please contact digres@mailbox.sc.edu. 


\title{
An Exploration of High-Risk Leisure Consumption through Skydiving
}

\author{
RICHARD L. CELSI \\ RANDALL L. ROSE \\ THOMAS W. LEIGH*
}

\begin{abstract}
A sociocultural approach is used to explore voluntary high-risk consumption. Specifically, we examine the dynamics of individuals' motives, risk perceptions, and benefit/cost outcomes of participation in increasingly popular high-risk leisure activities such as skydiving, climbing, and BASE jumping (parachuting from fixed objects). An ethnography of a skydiving subculture provides the primary empirical data. We propose an extended dramatic model that explains both macroenvironmental and inter- and intrapersonal influences and motives for high-risk consumption. Key findings indicate (1) an evolution of motives that explains initial and continuing participation in high-risk activities and (2) a coinciding evolution of risk acculturation that leads to the normalization of risk.
\end{abstract}

$\mathrm{T}$ wenty skydivers rise and line up tightly in single file, as the DC-3, cruising at 100 knots, levels off two and one-half miles above the swamps of central Florida. In their bright jumpsuits, they form a sort of surreal rumba line snaking toward the white light of the open DC-3 door. She is last out on this "twentyway" jump. Her job is to dive headfirst, in as fast and as controlled a manner as possible, to catch up to the skydivers exiting in front of her. Without exception the laws of physics will separate the skydivers as they exit, accelerating the first to leave away from those that follow. She lives for this. Nothing else exists for her now beyond this moment. The engines cut. Ready! Set! Go! She dives through the door. Like a body surfer, she rides the wave of the wind down and away from the plane. She descends head first, at vertical speeds approaching 200 miles per hour, toward the tiny cluster of skydivers below her. Tacitly judging distance and speed, she decelerates to perfectly match their slower fall rate. She does this by changing her body position from a dive to a flare, much like a bird landing or swooping in on prey. Gently, she settles into her assigned slot, taking a grip on the skydiver next to her. She smiles and calmly anticipates the next sequence in the dive; after all, the

${ }^{*}$ Richard L. Celsi is chair and associate professor of marketing at California State University, Long Beach, 1250 Bellflower Boulevard, Long Beach, CA 90840-1006. Randall L. Rose is associate professor of marketing, University of South Carolina, Columbia, SC 29208. Thomas W. Leigh is associate professor of marketing, University of Georgia, Athens, GA 30602. Special thanks are extended to Mary Wolfinbarger, John Sherry, Terry Shimp, Eric Arnould, Russ Belk, and three $J C R$ reviewers for their help. All correspondence should be sent to Richard L. Celsi. skydivers still have 30 seconds to perform in before impact.

As we imagine the thrill and marvel at this skydiver's courage or foolhardiness, we cannot help but wonder why she skydives. Why would an individual purposefully seek physical and psychic risk? A paradox seems to exist when individuals who, for example, wear seat belts, obtain the best personal and property insurances, use condoms, and seek safety and security in the workplace spend their free time risking it all climbing granitic escarpments, hang gliding, or falling earthward at 150 miles per hour in free-fall.

These questions gain in importance when we consider the rapid increase in the consumption of high-risk activities. For example, the United States Parachute Association (USPA) reported over 2.5 million parachute jumps in 1989, with the number of participants increasing nearly 20 percent since 1985 . Hang gliding and ultralight and glider flying have all blossomed in the past 20 years (Brannigan and McDougall 1983). Bungee jumping and mountain biking were unheard of 20 years ago, while activities such as scuba diving, ballooning, surfing, and white water rafting, canoeing, and kayaking continue to grow (Blau 1980). Not only have the numbers of participants in risk-taking activities increased, but the demographics of the participants have broadened to include a wider age range and an increasing number of female participants. The USPA, for example, reports a 62 percent increase in female membership since 1985 (C. E. Vincent, Director of Statistics, United States Parachute Association, personal communication, 1991).

Concurrently, the industries serving these activities have grown. For instance, 20 years ago, skydivers relied 
solely on army surplus equipment. In the 1970s, surplus gear was gradually replaced with parachute equipment designed and produced by skydivers themselves in a growing cottage industry. Today, parachute equipment and accoutrements are produced worldwide in a multimillion-dollar industry. Similar technological and industrial growth, as well as the development of publications dedicated to these sports, has coincided with most of the activities cited above (Lyng and Snow 1986).

Moreover, the styles and signs of these risk takers have touched us all. Mainstream fashions reflect the close-fitting aerodynamics and bright colors of biking, skiing, and climbing clothes. Everyday speech is punctuated with cliches that urge us to "go for it!" Daily, the media presents us with images of extreme skiing, bungee jumping, and hang gliding; while the voice in our television tells us over and over again that "there's a new breed of cowboy out there." Phrases such as "be all that you can be," have replaced the admonition to know thyself with a more strident call to live life to the fullest.

Thus, whether one is an actual participant, or an individual living vicariously with consumer goods as lifestyle props, the style and color of high-risk sports have become a badge of our times. We are all admonished to "just do it," and "play hard," for "life is short."

\section{HIGH-RISK LEISURE CONSUMPTION}

We are specifically concerned with the motivations, behaviors, and experiences of individuals who voluntarily seek high-risk activities. What defines and separates these activities from other freely sought leisure pastimes, or risky endeavors such as playing the stock market, is the acceptance of physical and psychic risk. Specifically, in high-risk activities participants knowingly risk death or physical injury as well as the possibility of psychic injury should they fail to perform adequately in the risk context (Lyng 1990; Mitchell 1983).

Illustrative of the risk is the number of high-risk fatalities reported in the United States from 1978 through 1980 (Society of Actuaries 1983). During this period an average of 49 skydivers (one per every 700 participants), 50 mountain climbers $(1 / 1,000), 122$ scuba divers $(1 / 100,000), 41$ ultralight aircraft pilots $(1 / 250)$, and 27 hang glider pilots $(1 / 1,250)$ were killed each year. Countless others were injured. This compares to a fatality rate of one out of every 200,000 participants in amateur and professional football during the same period. What makes these figures more startling is a comparison of risk exposure. For example, even highly active skydivers, given the relatively short duration of a single parachute jump, will rarely have more than eight hours risk exposure in a single year, while a football player may acquire that much exposure in two days of practice.

In sum, despite the dangers involved, an increasing number of individuals consume high-risk activities, and many others participate vicariously. Moreover, industries that support these activities are growing while the media increasingly reflects risk-taking behaviors. Why? What is the meaning of high-risk dramatic consumption? Why do individuals risk their lives for play?

Our goal is to examine high-risk consumption utilizing skydiving as our primary empirical focus. Our specific objectives are (1) to explore the context and phenomenology of the high-risk experience and (2) to examine the dynamics of motivation, risk, and benefits attained through participation.

We propose that high-risk activities are dramatic in form-structured with distinct beginnings, middles, and ends-and are to a degree motivated by a dramatic worldview (see Barnard 1968; Propp 1958). Specifically, we believe that high-risk behavior is fundamentally related to our inherent dramatic enculturation. Thus, we use a dramatic model as a conceptual framework for our exploration of high-risk consumption (Burke 1945, 1968; Goffman 1959; Werner and Schoepfle 1987). As such, our use of the dramatic model, building on previous use in the consumer literature (e.g., Grove and Fisk 1983), extends beyond metaphor to metatheory. We proceed with an overview of the dramatic model and key environmental factors that, we propose, combine to produce a context conducive to dramatic highrisk consumption. Second, we outline our empirical focus and research methodology. Third, we present our results. Then, we interpret and discuss our findings.

\section{AN EXTENDED MODEL OF HIGH- RISK LEISURE CONSUMPTION}

Factors external and internal to the individual coincide to produce high-risk behaviors. At a macro level, influences resulting from societal and cultural complexities, media enculturation, and technological change create a context that is more or less conducive to a behavior. Within this context, internal variables such as predispositions, goals, and psychological states and, to a large extent, interpersonal influence determine who will actually become a participant (Fig. 1).

To understand the manifestation of any behavior, however, it is first necessary to consider the effect of these variables relative to a society's unique cultural perspective. Our basic proposition is that in Western society the dramatic framework is a fundamental cultural lens through which individuals frame their perceptions, seek their self-identities, and engage in vicarious or actual behaviors. As such, the dramatic model is the foundation of the Western imagination (Barnard 1968; Propp 1958).

In its most fundamental form, the dramatic construction, which stems from Greek theater, pits protagonist against antagonist in a structured and discrete context that progresses temporally through periods of tension building to denouement and catharsis. In the first stage, or agon, conflicting forces are introduced 
FIGURE 1

AN EXTENDED MODEL OF HIGH-RISK LEISURE CONSUMPTION

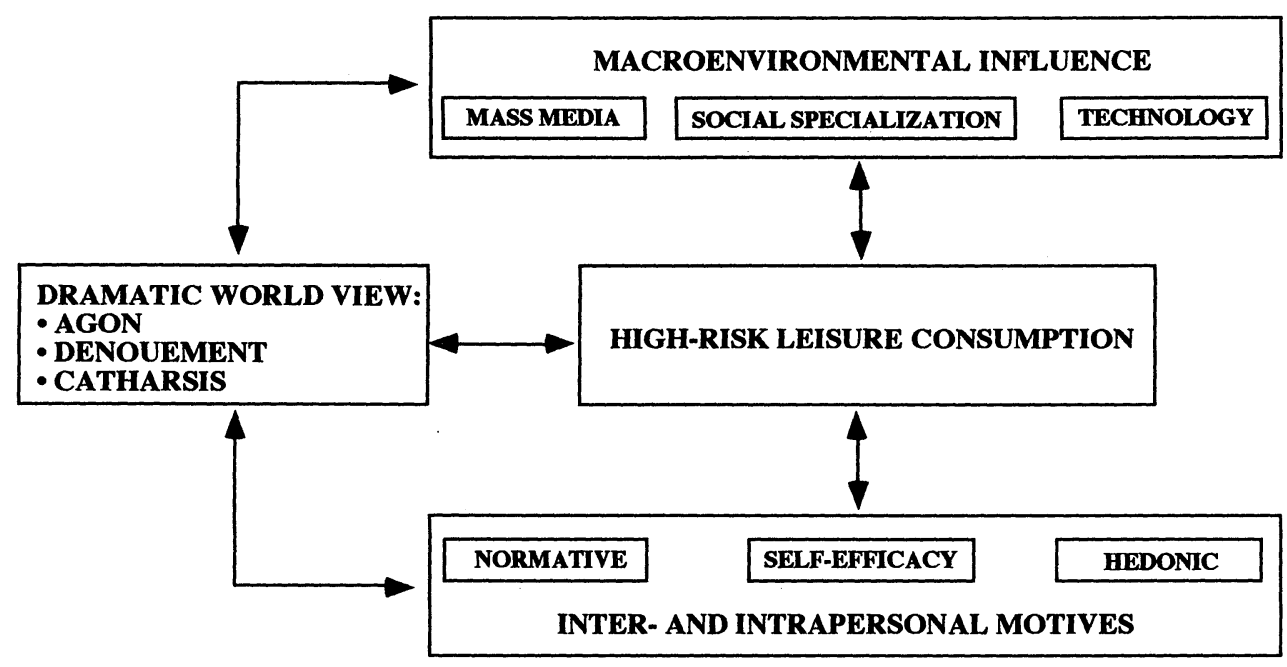

(good vs. evil; life vs. death; man vs. nature) and a tragic or comic context is defined (Brown 1927, pp. 80-81; Cheney 1952). A period of tension building follows, which stresses the physical and psychic conflict that occurs between the protagonistic and antagonistic forces. This tension is internalized by the actors and audience until released through denouement and catharsis. Denouement (literally "untying") is the solution that resolves the conflict, while catharsis, an emotive release resulting from denouement, refers to a figurative purification or "cleansing of emotions."

Relative to the dramatic model, we believe the interaction between three key environmental variables has effected a context conducive to risk taking as a leisure pursuit in the twentieth century. These are (1) the mass media, (2) social specialization, and (3) technology. Important to remember is that these are global factors that in themselves are not necessarily causal of specific behaviors but function to influence the context within which a behavior occurs. Next, we provide the reader with a sense of this context as a working framework to apply to our examination of high-risk consumption, which follows.

\section{The Mass Media}

In the twentieth century, the mass media and increased literacy have produced an exponential increase in the exchange of information and a more homogeneous Western identity. Fashions, events, and social patterns are instantaneously shared, creating a common environment that tends to produce similar wants and needs (Campbell 1987).

The signature of this enculturation is the dramatic model. Intertwined in the structure and content of the mass media, the dramatic model both reflects culture and enculturates in a reciprocating interaction. As such, the mass media influence dramatic behavior in two important ways: first, by reinforcing the Western dramatic worldview and in the process creating universal expectations; second, by extensively and repetitively modeling an endless variety of tangible dramatic behaviors.

The Enculturation of a Dramatic Worldview. We begin our enculturation to a dramatic worldview at the time we hear our first story. But it is largely through the mass media that our affective and cognitive expectations are shaped, as dramatic story lines form the content of cartoons, comics, music, novels, film, and television. However, it is not only through the arts that the dramatic worldview is conveyed, but through most social exchange, including written and oral history, legend, play, the news, sporting events, and religion (Barnard 1968).

While we consciously attend to, and are influenced by, the content and story line presented in the media, enculturation also occurs through continuous exposure to the dramatic framework within which the overt story line unfolds. McLuhan (1965), writing of this subtle power of media, suggested that the form of a medium, as much as its content, is the message (also see Hall 1959). Thus, the dramatic structure of the media, as much as their content or story line, is the message of Western culture. While we consciously pay attention to the content of movies or novels, we tacitly adopt their dramatic framing as the structure of our worldview.

A Card Catalog of Possible Behaviors. While the dramatic structure of the mass media frames our perspective, the content of media provides concrete images of possible behavior. It supplies a collective imagination or catalog of specific behavioral possibilities replete with clearly associated rewards and outcomes. Tangible and concrete, these "visual frames," as shared units of vi- 
carious consumption, provide props, players, and behavioral templates for our imaginative fantasy (see Campbell 1987; Markus and Nurius 1986).

The key point is that, in the twentieth-century mass media, the musings of individuals, which were once largely abstract and imaginative fantasy, are concretely instantiated. Thus, possibilities that might never have been previously considered, including high-risk sports, become tangible behavioral alternatives. ${ }^{1}$

\section{Social Specialization: The Amorphous Society}

A second contributing factor to the increase in dramatic consumption is social specialization. In sharp contrast to the clearly delineated and resolute form and needs of a dramatic worldview, postindustrial specialization increasingly disaffects and disfranchises members (Mills 1959). Most jobs and roles do not readily provide individuals with definitive outcomes and a sense of their role in cause-and-effect relationships. Forced to specialize, people lose autonomy and are distanced from the products of their labor (Durkheim [1848] 1951; Marx [1867] 1972; Mills 1959). As a result, blueand white-collar workers alike feel no strong sense of self and self-efficacy as a function of their labors (Edwards 1979; Lyng 1990).

Increasing the tension felt by these individuals is the juxtaposition of their dramatic worldview with the specialized context found in the bureaucratic workplace. The dramatic model, because of its inherent structure, primes individuals to seek denouement, rather than to fatalistically accept the tension of alienating circumstances. Thus, many Westerners, rather than viewing their jobs as some Orwellian dead end, perceive them to be instrumental to the attainment of pursuits that provide missing autonomy and self-definition (Mead [1934] 1950; Turner 1976). The workplace itself then becomes part of the overall dramatic model, providing tension to be released, and the means, such as discretionary time and income, to seek denouement through play. $^{2}$

\footnotetext{
${ }^{1}$ A clear example of behavior directly related to concrete depiction appears in Schouten's (1991) ethnography on self-enhancement through plastic surgery. Here, a woman becomes convinced to have surgery when she watches a surgeon "retouch" her photograph with a pencil. Schouten interprets that "the retouched photograph . . . created a more concrete set of expectations . . . and heightened [her] sense of longing for a more attractive self"' (p. 420).

${ }^{2}$ Clearly, men and women must also have the ability to seek alternatives, such as those provided by political freedom, mobility, and discretionary time and money, which are uniquely available to the Western general population in the twentieth century. These factors, however, are not unique to our propositions. For example, in Eastern societies, such as Japan, which are predominantly fatalistic rather than dramatic in perspective, feelings of alienation and search for alternatives appear only to occur, regardless of the "ability" level, to the extent that the individual has adopted a Western cultural perspective (Anderson and Watkins 1991).
}

\section{Possibility through Technology: Props for Play}

Technology also contributes to the increased consumption of dramatic high-risk activities by making some possible (e.g., aviation activities) and others more feasible and attractive (e.g., rock and mountain climbing). Improvements in materials and construction have increased safety and lowered costs. For example, skydiving equipment 25 years ago was awkward, weighed nearly 50 pounds, and provided little control with hard landings. Today, parachute gear is light (20 pounds), attractive, and so reliable that some people have made over 1,000 jumps without a malfunction.

A parallel exists with most high-risk sports. Hang gliders, which used to collapse in flight, are now made of stronger, space-age materials. The breaking tension of climbing ropes and harnesses has increased exponentially; crampons, ice axes, and tents are lighter. Clothing is warmer, lighter, waterproof, and wicks moisture from the skin surface.

Moreover, high-risk equipment, transcending function, has become stylish in form as manufacturers recognize the elevated status that participants bestow on it. Parachutes, climbing harnesses, cross-country skis, and ice axes have become props in dramatic plays enacted in the theater of our mountains, skies, or minds. Equipment is sacralized and given special status as extensions of self in individual life plays (Belk, Wallendorf, and Sherry 1989; Mead 1950; Solomon 1983).

Thus, our thesis is that the juxtaposition of the Western dramatic model with the specialized social forms of the twentieth century creates a context of motivating tension that requires outlets that are prototypically dramatic in form. This, coupled with the behavioral alternatives presented in the mass media, and the instrumentality provided by technology, creates a context conducive to dramatic high-risk leisure behavior.

\section{AN EMPIRICAL EXAMINATION OF SKYDIVING: METHODS AND PROCEDURES}

The primary empirical venue that we use to explore high-risk consumption is skydiving. We chose skydiving because of its (a) obvious prominence as a high-risk behavior, (b) clearly defined and accessible social-cultural structure, and (c) appeal to both participants and nonparticipants alike. Few activities strike nonparticipants as more antithetical to normal impulse than the act of willfully stepping through the open door of an airplane miles above the ground-all instincts say "No," yet, and perhaps because of this, the act is fascinating.

Our objectives are to observe, record, and interpret the phenomenological experience of (1) membership in a high-risk subculture, (2) the high-risk act, and (3) the meaning of skydiving to the participants. Specifically, 
we examine how and why these individuals skydive, their risk perceptions, and how they assign meaning to the death of a fellow skydiver.

We used a sociocultural procedure of comparative analysis as our general framework (Glaser and Strauss 1967; Werner and Schoepfle 1987). This methodology included (1) extended prior ethnography and (2) multiple-staged data collection, which was iterative and guided by an emergent design (Lincoln and Guba 1985).

The focus of this study was a skydiving drop zone (DZ) that we will call Southern Skies. From our research perspective, this $\mathrm{DZ}$ was a focal point for a society whose consumer culture evolves from and centers around the voluntary, high-risk behavior of skydiving. Supplementary ethnography included participant observation at over 20 skydiving sites throughout the United States and Europe (e.g., Celsi 1989). Direct participant observation by the first author of mountain, ice, and rock climbing, and aerobatics, as well as observation of hang gliding, light aircraft and gliders, and BASE jumping also provided grounding. ${ }^{3}$

\section{The Research Team}

Three researchers conducted this study, which has spanned five years at the time of this writing. The first author, a participant observer, (1) gained initial entry to the skydiving center, (2) established a trustworthy relationship with the informants, and (3) obtained permission from the owners and gatekeepers of the DZ to conduct the study. The second and third authors were nonparticipant observers who provided triangulation throughout the study.

\section{Prior Ethnography: Prolonged Engagement and Persistent Observation}

Because members of the skydiving culture tend to believe that outsiders view skydiving as semideviant, extended prior ethnography to build trust and acceptance is necessary. To attain prior ethnography, the first author, throughout the entire study and for approximately one year before formal data collection began, engaged in participant observation. Participant observation initially included training and safety classes, progression through student jumps, and attendance at social functions in addition to general immersion in the culture. During this period, the first author experienced several "rites of passage," such as (1) making a night jump, (2) water training, and (3) earning a master's or D license (proficiency licenses progress from A

\footnotetext{
${ }^{3}$ BASE (Buildings, Antennas, Spans, and Earth) jumping is where parachutists jump from fixed objects such as cliffs and bridges relatively close to the ground. This activity is considered by all to be much more dangerous than skydiving from an airplane. In fact, it is not sanctioned by the USPA, whose guidelines state that all parachutists should initiate their parachute opening procedure no lower than 2,000 feet above the ground.
}

through D). As his skydiving skill level and peer acceptance increased, he gradually attained group membership. Ultimately, during the course of this study, the first author made over 650 skydives.

After this initial period, the second and third authors came on site. Their first weekends on site were spent purely in ground observation and in meeting many of the skydivers. After several weeks, they both observed the skydiving performance from the air. They sat directly next to the ultimately opened airplane door, wore parachutes (required by law), and witnessed the actual skydiving act from 10,000 feet.

In summary, during the 30 months of prior ethnography and data collection, the authors observed the informants in all seasons and contexts-in the air, on the ground, socially, at different locations, at competitions, over a beer and laughter, and through the death and funeral of a key member of the DZ.

\section{Data Collection and Data Analysis}

Initially, we immersed ourselves in the overall skydiving culture both in situ and through secondary data sources such as USPA reports, manufacturers' brochures, magazines, journals, training films, and skydiving videos. During this period of prior ethnography, we conducted approximately 100 informal interviews, recorded 500 photographs, and videotaped 50 skydives, which we used mainly to document our observation (cf. Collier and Collier 1987).

Following prior ethnography, 35 individuals were interviewed in depth before saturation through informant redundancy was attained. These interviews, conducted over a period of one year, were tape-recorded and transcribed, producing 500 pages of single spaced data.

Emergent design and iterative procedures guided both data collection and analysis as we allowed hypotheses, themes, and inferences to develop from observation, informant responses, and researcher interaction (Sherry 1990; Wallendorf and Belk 1989). Primarily, we used a constant comparative method of data analysis (cf. Glaser and Strauss 1967). In this process, we continually analyzed the data as we collected it for categories and emerging themes, which we then used to guide subsequent data collection. Because of the lag in having taped interviews transcribed, this was initially done by listening to the tapes and reviewing notes, then comparing and discussing both notes and observations with coauthors. As transcripts became available, each author independently coded the data for thematic content and base "properties," which were then organized into successively broader and more abstract categories. Individuals with varying methodological backgrounds were then asked to provide direct feedback concerning our thematic categories. Through consensus we combined our analyses into a hierarchical framework that yielded our interpretations.

Environmental factors also influenced data collection. For example, when a skydiver from another DZ 
visited the research site, we made every effort to interview him or her. Also when a key member of the DZ was tragically killed in a skydiving accident, we sensitively explored the incident.

\section{Theoretical Sampling}

We initially selected informants who represented all key elements of the skydiving society. Our informants represented all levels of skydiving experience, ranging from initiates before their first jump to 25 -year veterans who, in their own words, "had seen the evolution of skydiving" (wm 45). As the analysis unfolded and themes began to emerge, we increasingly sought informants who could provide the greatest insight into these areas.

\section{Triangulation and Member Checks}

Triangulation was incorporated into all stages of the research (see Hill and Stamey 1990). Specifically, data from multiple sources and sites were collected and analyzed by three researchers using methods that maximized the benefits of triangulation. Furthermore, while all three researchers participated in all phases of the research, a second, more subtle triangulation of the level of researcher involvement was also purposively constructed. Specifically, the frames of reference of the researchers varied along a continuum of involvement with skydiving (see Celsi and Olson 1988). The first author was highly involved as a participant observer. The second author was a nonparticipant observer who had extensive on-site interaction with both the informants and the first author but was not part of the skydiving community. The third author remained a more distant observer of both the informants and his coresearchers. This layering of researcher involvement provided a combination of both expertise and reality checking. Also, member checks were conducted when 10 informants plus members of other risk communities (e.g., mountain climbers) commented on our results.

\section{RESULTS: THE SKYDIVING EXPERIENCE AT SOUTHERN SKIES}

In this section, we report an abbreviated "thick description" of Southern Skies. We focus on the experience of the high-risk performance itself, the key roles, and the leading players. As such, our report of the setting, props, operational roles, and the many secondary performances is necessarily limited.

We present skydiving's main act as a dramatic performance, with two stages of behavior (Goffman 1959; Grove and Fisk 1983). The front stage includes the physical setting (the buildings, runways), props (airplanes, parachutes), actors (skydivers, pilots), performances (free-fall, canopy ride), and audiences (the self, fellow skydivers, observers, members of the media). The back stage is a metaphor for the area where skydivers shed roles, rehearse, and privately interact.

\section{The Set and Immediate Audience}

Southern Skies (established in 1985) is a business run by two individuals who are skydivers, pilots, and instructors. Located in the rural South, the DZ occupies the north side of a lightly used airport. A single prefabricated building is used for $\mathrm{DZ}$ administration, equipment management, and instruction. The center of skydiving activity is a large blue nylon tarpaulin that formally serves as a packing mat. Across the runway is The Peas, a circular pit filled with pea-sized gravel, used as a target for landing accuracy and a landmark for "spotting" exits from the airplane. On a typical day, as many as 40-50 people enjoy the performance; half are skydivers and half are observers. "It's a big family. I guess that's probably what keeps me coming back a lot. I can just come out here to be with my friends and enjoy the day. Everybody's real friendly" (wm 27, 21 jumps).

\section{The Props}

The DZ's primary props are parachutes, jumpsuits, and two airplanes that can carry four skydivers each. Modern rectangular parachutes are airfoils with control lines to allow maneuverability. Jumpsuits are aerodynamically tight and typically color coordinated with the wearer's parachute gear.

Helmets, automatic activation devices (AADs), altimeters, helmet glow lights, goggles, and logbooks are other props. Helmets are worn by most skydivers. The AADs open the reserve parachutes of individuals who fail to activate their main parachute. These devices are required for students: however, they are typically rejected by experienced skydivers because they sometimes open prematurely and become a liability in group freefall. Goggles are needed because of wind speeds in freefall. Wrist altimeters supplement visual altitude checks. Helmet glow lights are used for night jumps. Logbooks are the personal diaries of skydivers. Videocameras and still cameras are used to document the skydiving drama and folklore, and for teaching.

\section{The Players}

At Southern Skies, we met jumpers aged 16-62. We interviewed bankers, factory workers, accountants, artists, teachers, social workers, construction workers, welders, salespeople, students, and lawyers. As one female jumper put it, "Skydiving is an equal opportunity sport" (wf 21, 250 jumps).

The Roles Played. The $\mathrm{DZ}$ social structure includes overlapping subgroups with roles based on experience (students, novices, intermediates, and experts) and roles 
based on function (owners, manifest coordinator, instructors, dive organizers, riggers, and pilots) predominating. Perceived competence is a critical factor in social status.

There is a social order in every DZ based on proficiency. In a large part, it is based on the number of jumps that someone has. You have the Jerry Birds [a very experienced skydiver] in every DZ where if they say something a jumper is going to listen attentively. Then, you have the guys who are just coming up. Every once in a while you have an exceptional student, or exceptional jumper with a low number of jumps. He can go up into that higher plane sooner. Then you have the professional instructors who are on a different level than the skydivers. They get the admiration of the students, but, because they don't get a chance to jump as much with the experienced ones, they don't have quite the proficiency (wm $38,1,000$ jumps, head pilot). ${ }^{4}$

Role Transitions. Acceptance into the skydiving community is marked by rites of passage. These milestones are experience based and are celebrated in ritual fashion. These events are not equally meaningful, and some (e.g., first jump, 1,000th jump, 12 hours free-fall) are more formalized than others (e.g., first four-point, four-person relative work [RW] dive).

The most obvious rituals honor the firsts in the skydiver's progression toward competence. The first jump is an initiation ceremony, often attended by friends and relatives. The first jump is best described in a novice's words.

I don't think I slept very much that night. They showed us how to get in and out of the aircraft. They just kind of built it up even more, and then we had to sign up and I found out [that] I'm on the twentieth load or something. So it took quite awhile, and I watched a lot of people come down before I got to go up. Finally, it was my chance to go up. I went with two friends. I volunteered to go first. I was really scared, looked at my friends and they were really scared too. The instructor didn't look scared at all. I looked at my altimeter. It kept going up to that 3,000-foot mark, and I knew that it was just about time to get out. I'll never forget the time that he opened the door. He yelled, "Door!" and then they opened the door and all the wind rushed in. That's when I started getting really scared. I watched him; he looked out the door, sticking almost his whole body out the door. His face was all distorted from the wind blowing his cheeks. You could just see that he wasn't scared at all. I said, "Gosh, it would be nice to be like him. When he jumps, he's not scared at all." Then, right around there, I guess, everything just kind of fell into place. I wasn't really scared anymore after he said, "Cut the engines." Then everything was like being a robot or something, because he told me what to do. He said, "Get in the door." I got in the door just like I was told. He told me to go all the

\footnotetext{
${ }^{4}$ While the number of jumps made is the most common criterion for experience, accumulated free-fall time is a better measure of inair proficiency. Currency of experience and safety consciousness also determine status.
}

way out on the wing. I got out there, climbed all the way out, hung [from the strut], and then looked back at him. Right at that moment I asked myself if I really knew what I was doing. Then, he said, "Go!" and I let go. The only thing that I could remember when I let go is, "You really did it." So I was thinking to myself, "You really let go." It was inconceivable right at that time. It was just one second or something, [but] nothing registered. I had no concept of what was going on, and all of a sudden my chute was open. After that I must have had this big grin on my face, ear to ear. It was my first time under a canopy, and I was playing around. I heard [on the radio], "Jumper number one, you have a good canopy." Then they asked me to do a 90-degree right turn, and they told me to play around a little bit. It was great. I came in [and] fell down on my first landing. It wasn't any big deal. I just loved it the whole time. They came out and met me and asked me how it was. I told them that it was great and that I was really excited about it. I stuck around for the rest of the day and watched all the rest of the jumpers come in. [wm 20,34 jumps]

The next significant event is free-fall. The first freefall jump is called a "hop and pop" because jumpers simply let go of the strut and immediately self-deploy their parachute. This first free-fall is the first truly selfcontrolled jump, and thus often produces more anxiety than the initial jump, causing some novices to quit the sport.

"Getting off" student status is analogous to completing an apprenticeship. Ritual pies find the face of new graduates. Acculturation continues as the novice jumper gains confidence, accumulates a logbook of experiences, and receives peer recognition for competence. Other significant events include the first night jump, the first water jump, the 12-hour free-fall badge, the 1,000 th jump, and earning skydiving licenses.

\section{The Performance}

Skydiving is a multiact performance and, like theater, takes many forms. The most popular are RW and freestyle. Relative work, a choreographed dive of two or more people, is so called because skydivers fly relative to one another and form various formations called points. Freestyle, relatively new, and free form, incorporates dance and gymnastic movements and, like freestyle skiing, is typically performed solo. We focus on the main events of an RW dive: dirt dive choreography, ascent, exit, free-fall, canopy ride, and aftermath. This sequence of events is typical of most skydiving performances.

The Dirt Dive Choreography. The opening act of $\mathrm{RW}$ takes place on the ground, typically with four players. The dive organizer casts the jumpers according to ability, choreographs, and directs the dive. A dress rehearsal is necessary, as skydivers use the colors of their team members' jumpsuits for in-air orientation. Observers see a curious dance near the packing mat. Skydivers "resemble gargoyles" (second author's field note) 
with hands in the air and backs arched as they move together, touching each others' jumpsuits, then separating, turning, and reuniting as they simulate the points of the dive.

The Ascent. To outsiders and novice skydivers, the thought of jumping out of an airplane is discomforting. Experienced skydivers, however, are typically only anxious on the ascent, as plane takeoffs (the most dangerous aspect of flight) are when these skydivers feel they have no control. At 2,000 feet, however, tension eases, as most experienced divers now feel they could jump safely in the event of a problem.

During the 30 -minute ascent, most divers mentally review safety procedures, although joking and kidding around is common, while many even sleep. However, as the plane turns on jump run, all skydivers report a surge of anticipation and excitement (see Fenz and Epstein 1967).

The Exit. The skydiving exit signals irrevocable commitment. The jumper must ultimately act to open the parachute and manage the descent, or die. Thus, as indicated in the following experience-level verbatims, the exit is a barrier to be overcome by novices and a form of denouement for experienced skydivers: "The getting out and climbing out and holding on and letting go with my feet was the scariest thing for me to do" (wf 25, 41 jumps). "It's like nothing I've ever done before. It's hard to put into words, the anticipation in the plane, getting ready. One of the greatest parts of the jump to me is hanging outside of the plane, listening to the count. When I hear ready, set, go, the excitement is so tremendous" (wm 30, 100 jumps). "I had 1,500 jumps when I made my first C-130 jump. It was almost like making my first jump all over again. We didn't know what to expect, and that thing went so fast [even] with 150 skydivers on board. When that tailgate started opening, the adrenaline was flowing, and you just thought: 'What have I gotten myself into here?' When you leave that thing it's like somebody rams you in the rear and kicks you across the sky" (wm 43, 1,800 jumps).

Free-Fall. Free-fall is the action of skydiving (Goffman 1967). Free-fall is fun, exhilarating, and free. Skydivers refer not only to the freedom to traverse the sky, to fly, but also freedom from everyday cares. This sense of freedom derives from the intensity of involvement required to carry out complex RW maneuvers, or, for novices, simply through achieving stability in the air. Jumpers at all experience levels report a loss of selfawareness gained through free-fall. "When I'm in freefall, I don't think about anything else in the world. I'm not thinking of any problems. It's just kind of an escape that's just free. You're just flying"' (wf 25, 42 jumps). "Freedom. I think of that more than thrill. You get a lot of fun out of it, but there is something fast-paced. You're thinking in split seconds. Everything seems to be in a time warp. Everything slows down. It's total concentration. To me it's completely relaxed because everything else is off your mind" (wf 35, 1,600 jumps).

Outsiders imagine free-fall to be the scream-eliciting, gut-wrenching acceleration felt on a roller coaster. However, skydivers describe the experience of free-fall as having little sensation of falling. Under normal conditions, the following is typical: "I have no sensation of falling. That's something that surprises me. In a dream, I have fallen before. You have that horrible feeling of falling. I don't experience that at all. I mean, when I'm in free-fall, I'm floating. I feel like I'm lying on a cushion of air, and I float. I have no sense of speed, because the people I'm jumping with [are] at the same speed. Everything is relative. It's not a sensation of falling. It's more like I'm flying" (wm 27, 100 jumps).

In contrast, when skydivers open too low (below 2,000 feet) because of error or malfunction, they report "ground rush," a perception that the earth seems to leap up at them. Skydivers who have nearly "gone in" (i.e., died in a skydiving accident), but managed to open their reserve, claim the horizon began to close around them, "like a book being slammed shut."

Under Canopy. Free-fall ends when the main canopy is successfully deployed at $(4,500$ feet for students, 3,500 feet for novices; 2,500 feet for C licenses; and 2,000 feet for D or master licensed skydivers). Opening low is risky since there are only about 11 seconds to impact from 2,000 feet while falling at a rate of 176 feet per second.

Canopy activity is described with less fervor and excitement than free-fall, with some experienced skydivers even viewing the canopy ride simply as a means of getting to the ground. Most jumpers, however, find the canopy ride to be relaxing and peaceful. Novices especially seem to enjoy "flying" their canopies. The relative perspectives of novice and expert seem to reflect their varying comfort levels. Novices struggle with stability in freefall, do limited relative work, and often jump alone. The canopy ride provides them with a sense of relief and control, along with a novel view. "This is the part I enjoy the most, being on a canopy. Then I got into the thirty- and forty-five-second free-falls. That was fun. But I enjoy being on a canopy; it's real peaceful. With the limited experience I've got, that's probably the most pleasurable part. It's not as exciting as freefall, flying with somebody, but it's a peaceful feeling being up there floating above the earth" (wm 27, 21 jumps).

Divers report a sense of relief as they confirm a good canopy above their heads. These divers make the obvious but important point that jumpers must take appropriate, timely action to save their lives by deploying a parachute. Thus, a good canopy, like the attainment of the 2,000-foot altitude after takeoff for experienced skydivers, punctuates the end of an anxiety spike (cf. Epstein and Fenz 1965). "When my chute opens, I feel 
good. You have fun free-falling, but, as long as you're in free-fall, you're still plunging to your death until you throw out that pilot chute. When I open up, it kinda gives me a good feeling" (wm 36, 110 jumps).

While free-fall is only easily visible to other skydivers, parachute landings are public performances. This is why outsiders see skydiving largely as a parachute-related sport, while skydivers tend to view airplanes as an elevator to free-fall altitude and parachutes as a way to get down.

Postperformance Rituals. The post-dive ritual provides important performance feedback and peer evaluation. Jumpers dissect the dive in detail. Backslapping and other displays of emotion are common. After the final dive of the day cast parties often develop. These parties are backstage and open only to skydivers and their friends and family. Away from the DZ, many skydivers note that their feelings are enduring: "The actual free-fall lasts only about a minute, but the actual feeling lasts much longer than that. When I land, I'm still so up from the jump, so excited. When I go home after three or four jumps in a day, I'm still feeling the thrill and excitement. As I talk to other people about my skydiving, I get myself all worked up just thinking about it. It's something; the feeling just carries over" (wm 30, 100 jumps).

Performance Interruptions: Incidents on Stage. Human error, equipment failure, and random events have serious consequences in high-risk sports. At Southern Skies such incidents included a midair collision of canopies, a number of malfunctions and reserve rides, hard openings that yielded minor injuries, and a crash landing in which a co-owner of Southern Skies broke her legs at mid-thigh attempting to land a new and fast canopy. A major tragedy occurred when a skydiver failed to open either of his parachutes and was killed.

In this incident, a skydiver of moderate experience "went in" while participating in RW. Awareness of his death was very high. Seven of our respondents were on site when it happened (two were on the dive). The story spread quickly to the entire Southern Skies community.

The problem was initially noted by an audience of observers who were watching. Two witnesses described the events: "Yes, I remember. There were three students that first spotted that there wasn't a canopy. And he [one of the students] said, 'Wait, there is no canopy up there.' I was like, 'Hmm, you're right, maybe it's on the way.' We kind of made all kinds of rationalizations" (wf 21, 250 jumps). "The day he went in, I jumped with his daughter. As he was going up in the airplane, she said, 'I want to watch his jump.' So I was watching [and] one of the students said, 'Only three came out and I know there were four on that load. I'm sure there were.' I told her don't worry, you know, he could have opened low and you just don't see him. He's on the other side of the trees. He found a place to land over there. She and I were standing there. Her mother was here and her boss, her dad's boss . . . with their kids, and the kid was saying, 'Where's Uncle Mark . . . which one's his canopy? Where is he, where is he?" (wf 29, 42 jumps).

These incidents are important for at least two reasons: (1) they are a recurrent aspect of the skydiving experience, and (2) they provide a basis for insights concerning how skydivers view and deal with issues of risk and death, which we discuss following the next section on motivation.

\section{EVOLUTION OF MOTIVES}

In this section, we analyze the evolution of motives for high-risk dramatic consumption, which we proposed are influenced by macroenvironmental as well as interand intrapersonal factors (see Fig. 1). At the macroenvironmental level, we stated that (1) the mass media, (2) social specialization, and (3) technology, in interaction with the dramatic model, combine to produce a context conducive to high-risk behavior. Since these factors create a generalized motivational context, we expected them to have a largely tacit effect on people and thus rarely to be specifically mentioned. Close examination of the data, however, revealed several statements that directly supported our expectations.

For example, the following respondents mentioned drama presentations in the mass media as their initial motivation. "Remember the old TV show "Ripcord"? Well, I saw that once when I was little on TV and I thought I would always want to do that" (wm 25, 1,400 jumps). "I read an article in Readers Digest about skydiving and I also saw a show on TV" (wm 21, 34 jumps). "There was a Minolta commercial a long time ago where this girl was in free-fall and they were passing this camera around and it would kind of be floating there next to this person. Remember that commercial?" (wm 39, 1,700 jumps).

Informants also made numerous mentions of the tension emanating from the workplace and the release and catharsis they gained from skydiving. "My work is hectic. I'm paid by commission, which is stressful. Skydiving is a release, it relaxes me" (wm 28). "Free-fall is my way of letting tensions out I've gathered through the week" (wm 26). "The minute I throw my gear in the car, that's all I think about. I don't think about work, paperwork, or sales. Period. I release everything" (wm 32). "I tell my colleagues at the bank, who think I'm a nut: 'Look, you go home and feel very stressful from working here at the bank eight hours a day, five days a week. When I skydive, I totally forget that stuff"' (wm 44). Still other informants noted the instrumentality of their jobs to high-risk consumption. "I work for the weekend. I work to make a living and to make jump money. The DZ is the enjoyable part of my life" (wm 23, 325 jumps). "I'm part owner in a construction 
company; we do brick and concrete work all over the state and I try to work near where I can jump. You know, I start looking at the money I earn in terms of skydives . . . you go to buy something and say, now that's three skydives" (wm 36, 150 jumps).

Statements of technological influence were also made by those experienced enough to witness its evolution. "The sport has evolved into a much safer sport, the equipment is much better. The equipment has changed the sport, it has made the sport more acceptable to the general public" (wm 42, 1,880 jumps, owner/operator). "There's been very big changes, mostly in the safety aspect. It's become so much safer to jump. There's a much lower malfunction rate for the 'square' parachutes. It's just much easier and safer and attractive to people. Just like water and snow skiing, and any kind of sport, you know . . . the colors, everything is more appealing now days" (wm 34, 1,038 jumps, pilot).

From a woman's perspective, the technological change was imperative for female involvement. "They just had to make it more attractive to women. Because if we still had to wear big heavy rigs, it wouldn't be as attractive to a female. Women now have as much opportunity skydiving as men" (wf 21,275 jumps).

Moreover, during the time of this study there was a dramatic increase in the number of TV shows, like "The Extreme Edge" and MTV segments, as well as numerous ads, that depicted and glorified high-risk consumption. Also, in response to the increasing mainstream appeal of high-risk consumption, feature-length movies, such as Point Break and $K 2$, whose story lines focus on high-risk activities, were marketed to the general public. This overall increase in media exposure not only motivates trial and reinforces continuing behavior, but reflects the reciprocating interaction between the mass media and culture. In sum, environmental factors clearly influence, and are influenced by, dramatic highrisk consumption.

At the inter- and intrapersonal levels of motivation, our data reveal a dynamic process of motivational change as individuals participate in high-risk activities. Specifically, motives that are initially concrete and normatively influenced become increasingly abstract and often transcendent as they evolve from experiment and thrill, through mastery and identity, to community and self-fulfillment.

\section{Motives for Getting Started}

Skydivers make their first jumps for a variety of reasons including curiosity, thrill seeking, social compliance, and a desire for adventure. While many gained awareness and initial motivation through the mass media, the most frequently stated reason for trying the first jump was interpersonal influence. More than half of our informants indicated that a classmate, friend, or relative influenced their decision to jump. For example, "It was [my boyfriend's] idea to come out here the first time. I guess I'd always wanted to jump, but it probably took somebody to come down here and do it, and then I started doing it" (wf 21, 250 jumps).

For many skydiving initiates interpersonal influence had its greatest effect in group situations, as several respondents first jumped with friends or with a college skydiving club. Some of these divers would not have jumped without the support of others sharing the experience. This suggests "group polarization," a phenomenon in which there is a change from a modestly positive attitude to a very positive one in the presence of peers (Myers and Lamm 1976). With regard to risk, Wallack, Kogan, and Bem (1962) noted that group polarization produced increased risk acceptance in group decision contexts. The words of a female sky diver illustrate. "There were twenty of us. One guy goes, 'Man, I've always wanted to skydive. Why don't we do that this weekend?' And we were like, 'Yeah, sure,' in one ear and out the other. Well, this guy organized the whole trip. I was so excited. It was something I would never pursue on my own. Five of us went, three guys and two girls. I can say one thing. It helped out a lot having them with me. I would never have done that by myself" (wf 27, 500 jumps).

\section{Motives for Sticking With It}

As with most deviant or semideviant activities, the initial decision to skydive has a strong normative, as well as the expected hedonic (thrill), character (see Hirschi 1969; Holbrook and Hirschman 1982). The motivation to continue, however, is complexly influenced by efficacy motives, the creation of a new self-identity, group camaraderie, and heightened experience. ${ }^{5}$

Efficacy. An important motivation to continue skydiving is a desire to develop technical skill for both personal satisfaction and social status within the skydiving community. Recognition of the skill-status relationship in association with increased jump experience results in a refocusing of attention from physical risk to performance anxiety. "In the beginning you're scared to skydive. You're scared to jump out of the planes. It's scary, scary, scary. But when you get to the point where you're scared you might mess up the dive, then that's when you're a skydiver" (wf 27, 500 jumps).

Thus, high-risk performers become concerned with their skill development and the perceptions others have of their skills. They learn quickly that inclusion on the most desirable dives comes with perceived competence.

\footnotetext{
${ }^{5}$ Reported reasons for not continuing are also diverse, ranging from lack of funds to overwhelming anxiety. However, two general categories were observed: (1) The initial experience was not pleasant as "thrill" became fear and/or pain when the individual experienced a hard landing, line twists, a bumpy plane ride, or was otherwise frightened or injured. Injury was also one of the primary reasons that experienced skydivers quit. (2) The individual was experimenting and had as a goal to try something like this once to prove that he or she could do it.
} 
"Screwing up" by failing to fulfill an in-air mission carries the sanction of exclusion from future desirable dives. "They call it 'axing.' You get axed off a load because you don't have enough jumps. Ben [an expert] is really like that a lot. He's so competitive. He doesn't want you on his dive unless you can prove to him that you're gonna kick ass. So, on a four-way dive I would get excluded because I didn't have as many jumps as they had. I hated [that]; that was a major problem for a long time" (wf 21, 250 jumps).

Beyond the desire for social recognition of competence, skydivers of middle experience also express an increasing intrinsic interest in mastering skydiving. "It just seems to get better as it goes, because you do get more relaxed and the fear subsides. You realize that there are all these challenges that you haven't met yet and that there's so much more that you can do and learn" (wm 25, 325 jumps).

Thus, achievement itself becomes motivating as participants recognize the instrumentality of high-risk activities to the attainment of higher-order values. Moreover, with increased mastery, the standard by which competence judgments are made by self and others also increases, thus providing an escalating scale of expectations that maintains high-risk motives over time (see Bandura 1982).

Attaining mastery also differentiates the individual from novice skydivers as well as nonskydivers. This gives the jumper a measure of status and attention within the skydiving community, as well as establishing a clear boundary between actor and nonparticipating audiences. Thus, there are externally derived motives for achievement in high-risk activities as well as intrinsic motives (Trope 1986).

Identity Construction. Beyond the obvious benefit of being different from one's everyday peers, which is provided by making a single skydive, sustained participation in a high-risk subculture offers the opportunity to construct a "new" personal identity (Belk 1988; Schouten 1991). In everyday existence, we are born into a specific sociocultural situation and proceed through life making determining choices based largely on uncertain information and sometimes unclear goals. As a result, we often arrive at our adult identity as much by circumstance as by choice. Moreover, it is difficult to change jobs, social status, or our social identities once our adult roles are achieved.

In contrast, high-risk activities provide a well-defined context for personal change, as well as a clear-cut means to organize a new, and sometimes central, identity (Markus and Nurius 1986). For example, rites of passage are concrete and clearly evident, with specific guidelines and requirements for their attainment. The initiate observes that what one is or does in the outside world does not pertain within the high-risk community. Rewards of privilege and status are direct and attainable with effort. Above all, one is recognized for one's overall mastery. Through long-term active participation, one becomes a skydiver, in a largely meritorious society.

The desire to create a new identity also helps explain a participant's drive for achievement and mastery. Identity construction requires commitment to a new set of life tasks with concrete plans and strategies of implementation (Cantor et al. 1986). The path to achievement is carefully scripted with well-understood benchmarks for evaluation of performance. These new life tasks are closely linked to participants' cognitive representations of the possible selves they seek (Markus and Nurius 1986). Thus, the promise of a new identity also provides a powerful motive for a commitment to mastery of high-risk activities.

\section{Transcendent Motivation: Flow, Communitas, and Phatic Communion}

With increased involvement, properties of high-risk motivation become increasingly abstract and transcend normal experience (Celsi 1992). We organize these transcendent motives into the following categories: (1) individual heightened experience, or "flow" (Csikszentmihalyi 1975), (2) transcendent group camaraderie, or "communitas" (Turner 1969; Turner and Turner 1978), and (3) special communication, or "phatic communion" (Fishman 1960; Malinowski 1923; Whorf 1940). These concepts underlie the sense of community and special identity that defines the skydiving subculture.

Flow. Informants describe the skydiving act as one of total absorption that provides them not only with thrill and excitement, but also a sense of involvement that transcends mundane experience. When asked why they skydive, they invariably say "because it's fun." When pressed, they collectively respond that nothing else exists in their world but that moment itself-no sense of time, just a kind of holistic oneness that makes them feel good and somehow changed.

This transcendent state, or "flow experience" (Csikszentmihalyi 1974), occurs when a situation demands total participation from the individual. As such, flow is a phenomenological state where self, self-awareness, behavior, and context form a unitized singular experience. Thus, flow is a state of total involvement where one moment "flows" holistically into the next without "conscious intervention" (Csikszentmihalyi 1974 , p. 58). In this sense, flow is transcendent and typically recognized by the experiencing individual as such only when the state is diminished (also see Mitchell 1983).

Csikszentmihalyi (1975) believes the flow experience is the manifestation of a person's "true" self, unconstrained temporally by convention or by self-awareness. Flow provides a sense of self and self-efficacy that is highly satisfying and self-fulfilling. Csikszentmihalyi 
and Csikszentmihalyi (1988) state that this is why the flow experience is so powerful and, once experienced, is like a siren with a now "realized" self seeking to continually self-replicate, or reexperience the state.

For example, the first author reports hearing a fellow climber say to no one in particular, upon reaching the 18,700-foot summit of Mexico's El Pico de Orizaba, "it [the mountain experience] calls you back over and over again" (wm 36). Skydivers use the same language to describe the sky. "I'm getting into different aspects of the sport now [e.g., flying the jump plane], but I still can't think of anything better to do than to come out here with my friends and make a skydive. It calls you back every time" (wm 34, 1,038 jumps, pilot; emphasis added).

For flow to occur the context and person must interact in a balanced, recursive fashion. That is, flow is most likely to occur when a context exists that pushes individuals to near their physical and mental limits, without overwhelming them. An unchallenging context will not motivate total involvement; an overwhelming one will break down the individual and produce anxiety (Mitchell 1983). In this sense, the components of flow are relative and are treated as such by participants in dramatic high-risk activities.

Key then to the attainment of flow is control over the relationship between the individual's abilities and the demands of the context. Knowledge of each is necessary for the individual to create a script likely to attain denouement and the benefits of flow and catharsis. In this sense, the dramatic act of skydiving, or any other high-risk sport, is a "set piece" that is enacted on a specified stage with a clearly defined beginning, middle, and end. The time, location, and players are carefully selected. Goals and outcomes are defined and agreed on. The script is rehearsed, with the tacit understanding that the truly able will be capable of "ad-libbing" when necessary.

However, it is the regulation of the degree of tension that is critical. It is here that the performer seeks to delimit the context, or "stimulus field," to a manageable level of uncertainty (Mitchell 1983). Clearly, uncertainty is necessary for goals to be a test of the ability levels of the actors; what is optimally desired is exquisite tension that falls somewhere short of sustained anxiety (Goffman 1967; Simmel 1968; Zuckerman 1979). Therefore, the context is varied relative to the ability level of the individual, allowing both the novice and the expert to perform within a range of optimal tension.

For example, skydivers plan a jump that tests their abilities. They set as a goal the attainment of a certain number of "points" in a single RW jump, or a certain number of people in a single formation, knowing that each member of the team must perform to the utmost of his or her ability to attain the set outcome. They also accept certain necessary risks, trusting their equipment, the aircraft and pilot, and especially their fellow skydivers. They try to limit uncertainty by jumping only with skydivers judged to have the ability to complete the prescribed jump, and only if the weather conditions are not threatening. They ritualistically check their equipment before entering and exiting the plane. They rehearse the dive on the ground. Thus, they carefully create a context of controlled uncertainty as a stage within which they can act.

Flow, then, is a state of total involvement that occurs within a stimulus field that is limited and scripted by the individual. As a benefit or end state, flow is cathartic, leaving individuals both satisfied and exhilarated, with a sense of self-authentication (Bammel and BurrisBammel 1982). It is a state where one is unaware of self-awareness, where homunculus, the voice within, has been silenced. Zen-like, individuals attain and sustain a period of accomplishment that transcends their normal level of efficiency; physical and mental activity are one. In this sense, flow is spell-like and has addictive qualities that summon individuals back over and over again. "It's really addictive to me and most of the people that I know that skydive. You know, like a drug or something, you want to experience it over and over again" (wm 36, 150 jumps).

Communitas. Communitas is a sense of community that transcends typical social norms and convention. That is, communitas is a sense of camaraderie that oo curs when individuals from various walks of life share a common bond of experience, such as skydiving and flow, that all participants consider special or "sacred" (Belk et al. 1989). According to Turner and Turner (1978) communitas is most likely to be experienced when individuals share a liminal state between two statuses. For example, communitas is likely to occur when individuals with varying backgrounds go on religious pilgrimages, join fraternal orders, or become members of counterculture groups (Sherry 1987). Thus, the spirit of communitas emerges from "shared ritual experience" that transcends the mundane of everyday life (Belk et al. 1989 , p. 7).

A key aspect of communitas is the recognition that everyday statuses and social roles are not relevant to the high-risk community (Turner 1969). As one informant put it, "Jumpers have a special kind of bond. You have your doctors, professors, lawyers, but you also have your truck drivers, bricklayers, and masons. Out here on the weekends none of that is a factor. What people do and how much money they make just doesn't matter. There's just this closeness here" (wm 25, 325 jumps).

Thus, communitas is a sense of shared ritualistic experience that transcends ordinary camaraderie. It constitutes a sense of belonging and a sharing of transcendent information. While flow is transcendent at the individual level of experience, common knowledge of the flow experience creates a bond between members. As such, Turner (1972) describes communitas as a "shared flow." 
Moreover, while communitas stems from the liminal aspects of different individuals sharing the overall highrisk experience, each skydive itself, in microcosm, can be seen as a liminal state between two environmental statuses-physical contact with the earth, plane, or parachute versus free-fall. In this sense, a liminal experience is replicable to all skydivers with each jump.

Phatic Communion. Tying together the high-risk subculture is a special communication that is also transcendent. It is a combination of shared experience and technical language that transcends translated meaning. As a special language it joins together members of the cultural community and is little understood by nonmembers. Comprehension of the skydiving "language" itself is held in high esteem, and is a sign of cultural membership.

Malinowski (1923) described this special communication within cultural groups as "phatic communion." Understood by insiders, it provides them with special verbal and nonverbal cues with which to create and communicate their special worldview. It is a communication that transcends common understanding and gives fluidity and cohesion to their subculture. Fishman (1960) observed that phatic communion is most likely to occur among "traditioned groups, particularly those sharing many intimate and heightened experiences" ( $p$. 328 ). Thus, the concept of phatic communion appears to capture the special communication between members of liminal groups and subcultures who in particular share ritualistic experiences. ${ }^{6}$

Whorf (1940; as cited in Fishman [1960], p. 325), writing about the relativity of language between cultural groups, said that "observers are not led by the same picture of the universe, unless their linguistic backgrounds are similar or in some way can be calibrated" (see Mick 1986). Similarly, Fishman (1960) referred to this nontranslatability as an issue of "differential codifiability" that is "often a correlate of distinct cultural patterns" (p. 328). He states that it is no wonder then that insiders feel that no other language "can cope with the very nuances of meaning and the very experiential patterns which are most significant to them in terms of their cultural distinctiveness. From this awareness, it is but a short jump to language loyalty and language glorification. . . There is a magic indeed in a language whose differential codifiability makes it peculiarly suitable for the expression of an individual's most central personal and cultural experiences" (p. 329).

Here, Fishman's notion of language glorification suggests the transcendence of the special communication to the realm of the sacred (Belk et al. 1989). That is, the communication, both verbal and nonverbal, that constitutes phatic communion is not only a means by

\footnotetext{
${ }^{6}$ Similar types of special communication are evident in many highrisk activities, such as mountain climbing, hang gliding, scuba diving, and aerobatics.
}

which individuals communicate the cabala of the group, but in itself is an aspect of communitas. Thus, phatic communion is itself transcendent as it provides a special language that describes the subculture and binds its members.

For example, consider the term RW, which translates to mean two or more people intentionally skydiving in free-fall in close proximity to each other. This fundamental skydiving term contains layers of meaning, much of which is incomprehensible to outsiders and rarely capable of being articulated by insiders in abstract terms. Beyond simple definition, the term captures a concept of pure relativity in free-fall, where movement and direction are in direct correspondence to the skydivers themselves, and not to an absolute. This in itself is beyond the complete understanding of the outsider or even the novice skydiver who cannot imagine a perception in free-fall that seemingly ignores the absolute proximity of the ground. "I feel like it's a whole other world . . . you're in this three-dimensional space and you're working with this space. I don't think about the ground at all" (wf 25, 425 jumps).

In this sense, $\mathrm{RW}$ is a grand illusion of temporarily and willingly suspended disbelief where the skydiver is free for 60 seconds to traverse free space. For example, skydivers speak of someone who has "gone low" on a formation as "coming back up" to the formation, although in absolute terms both the formation and the low skydiver are falling toward the earth, albeit at different rates of speed because of the body control of the low skydiver. With this relative perspective, the low skydiver does come up to the group. All skydivers will say, "To experience it is the only way to understand it."

Moreover, in RW free-fall, sensory information is relative to other skydivers. As a result, skydivers invariably report that they experience no sensation of falling. Of course, no skydiver ever completely forgets that he is falling, at least not living ones. "There's really no indication that you're falling other than you know it in the back of your head and you feel the breeze" (wm 25, 52 jumps).

The key point is that the experience of RW translates incompletely and poorly to nonparticipants. Moreover, even the latter description of RW is still at a concrete level and only represents a fraction of what RW is. The feelings and emotions of flight and control of space and self, plus the visual and tactile communication with other skydivers in flight, are rarely translatable to outsiders, nor are the more abstract feelings of flow, communitas, and the largely unarticulated sense that RW also somehow represents a philosophy and confirmation of the community. Much (if not all) is lost in translation to outsiders, but not among the participants themselves, who share communitas, and clearly recognize their special understanding. "Part of the reason there's such a strong camaraderie among skydivers is because we are, in a sense, 'social outcasts.' No one understands us and 
FIGURE 2

THE EVOLUTION OF MOTIVES FOR HIGH-RISK CONSUMPTION IN RELATION TO RISK ACCULTURATION AND EXPERIENCE

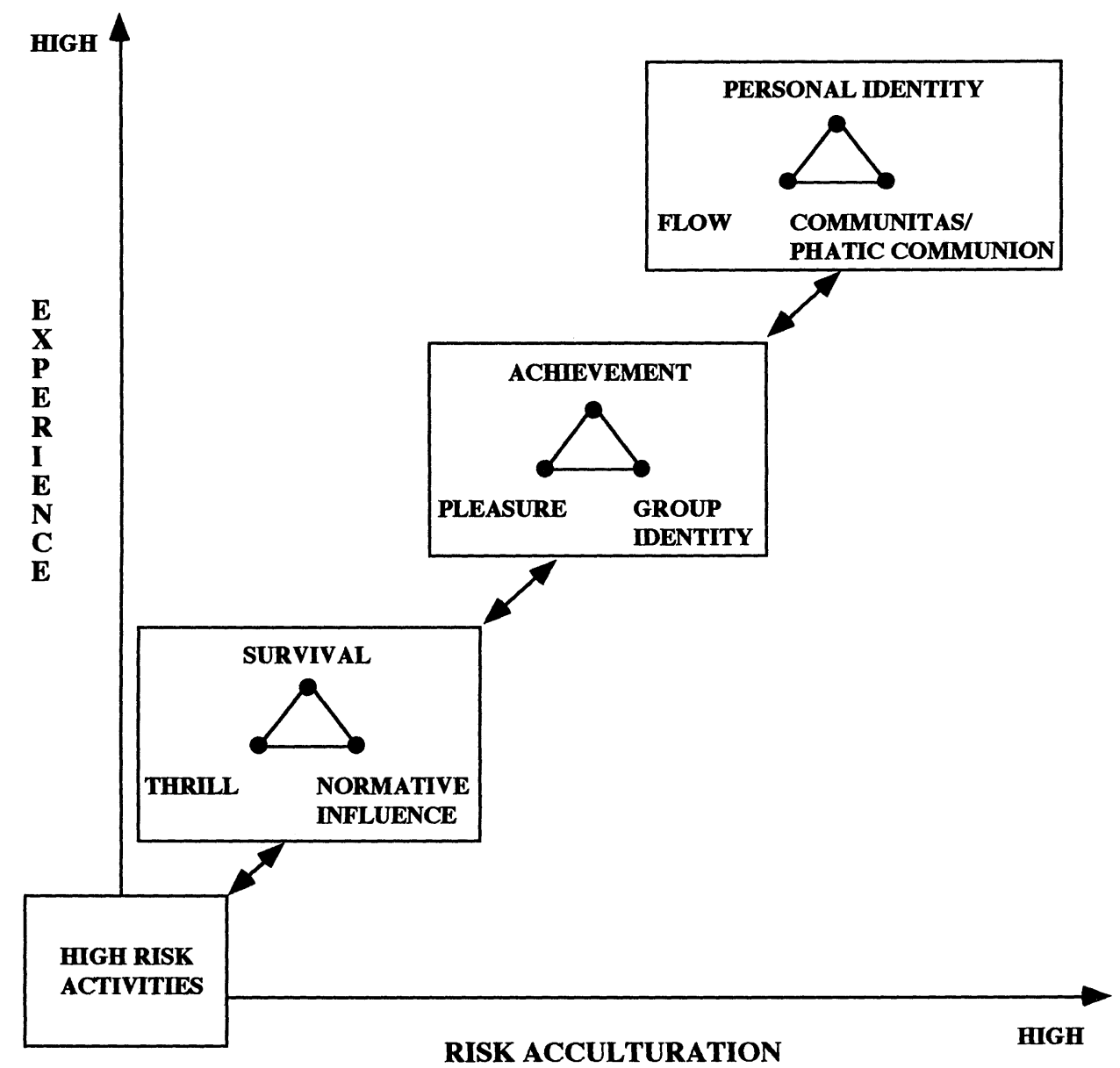

why we do it, only other people that skydive truly understand" (wm 41, 77 jumps).

\section{Motive Properties and Motive Trajectories}

The preceding analysis of motives indicates three general categories: (1) normative, (2) hedonic, and (3) self-efficacy. While these categories, in themselves, provide considerable insight into high-risk behavior, an interesting pattern of motive evolution is also evident. Specifically, both the level of involvement and the motivational properties underlying high-risk participation evolve over time (Fig. 2).

Normative Motives. The most likely reason for first performing a high-risk behavior is normative, as compliance with the desires or expectations of others is the key property of early involvement. With experience, normative motives continue to play an important role, but their basic properties change. The motivating power of compliance diminishes after the first experience and shifts to identification with the new subculture. Ultimately, the properties of normative motives evolve to include the transcendent end states of communitas and phatic communion. Once the participant is fully acculturated, the motivating powers of these transcendent properties are so strong that the group experience becomes an end in itself. Members often maintain association with the subculture even after circumstances such as injury, illness, or even inadequate financial resources constrain active participation.

Hedonic Motives. The evolution of hedonic motives follows a trajectory from thrill seeking through pleasure and fun to experiences of flow. While the thrilling properties of high-risk consumption, such as excitement and adrenalin, are never extinguished, their ability to arouse to supranormal levels diminishes after a threshold of repetitive experience is reached. However, as the participant begins to normalize fear and to develop the skill and mastery to maneuver in the air, somatic thrill is complemented by pleasure and fun. With developing 
mastery, which tends to free the participant from constant self-awareness, the primary property of hedonic motivation evolves to include transcendent flow states.

Efficacy Motives. Initially, concerns of safety and survival dominate. Once participants develop some degree of trust in their equipment and selves, however, skill development and achievement properties become the key aspects of self-efficacy. Learning to create and manage risk contexts is inherently empowering and efficacious. Development of control, achievement, and mastery build self-confidence and contribute to the construction of a new identity based on the high-risk subculture. Thus, the trajectory of change for the efficacy motives also ends with a type of transcendence, the partial abandonment of an old self for a new favored identity.

Thus, we propose three categories of motive evolution that we believe best describe motivation for high-risk consumption. Each motive trajectory is a series of increasingly abstract and desired end states. Each motive can be viewed as a personal value that is instrumentally linked to the high-risk activity (Gutman 1982; Olson and Reynolds 1983; Tolman 1932). As such, each level of motivation in each motive trajectory provides an escalating degree of motivation toward the high-risk activity.

However, the truncation of motives into categories is always artificial, as all of the above motive properties ultimately interrelate in highly complex ways. For instance, flow as a hedonic property linked to pleasure and the primarily somatic experience of thrill must also be linked to efficacy, which tends to free one from selfawareness, and to "community," which provides the context. Our specification of these properties as individual motive trajectories allows us to tease out their finer points and thus to more fully understand their generality. Ultimately, all of these interrelated properties in their full complexity constitute the highly abstract yet seductively simple meaning of "fun" as stated by high-risk consumers as reason for their participation.

\section{RISK, RISK ACCULTURATION, AND DEATH}

To fully understand the motives and meaning of highrisk consumption a corresponding examination of risk is necessary. Like motives, risk perceptions evolve with experience and become normalized as one assumes a high-risk identity. Our examination of risk reflects these dynamics.

\section{Simple Thrill and Risk}

Risk is typically viewed in Western society as the likelihood that the effects of a hazard will be experienced (Short 1984). Thus, risk is a negative thing to be avoided when possible and, when not, weighed against the probability of positive outcomes and benefits (Heimer 1988).
What makes dramatic sports interesting is that participants appear attracted to risk situations and, at least to the outsider, to view them as desirable. Hence, nonparticipants presume that the factor that motivates skydivers to take risks is the thrill and excitement that results solely from risk taking itself, and that the degree of thrill is commensurate with the degree of risk. In its simplest form, this perspective would hold that the thrill skydivers experience is directly proportional to the degree to which they "scare" themselves.

Novice skydivers also tend to see skydiving risk largely in terms of the thrill and euphoria that result from the risk act itself. Their experience with risk beyond basic outcomes is minimal, while their motives have not evolved beyond excitement. Thus, they tend to singularly equate thrill with risk.

Opponent Process Theory. This affective contrast of thrill and risk, or pleasure and fear, is the key process in Solomon's (1980) opponent process "theory of acquired motivation." Solomon believes that motives for behaviors such as thrill seeking, love, power, food cravings, and heroin addiction, for example, are acquired over time, have a hedonic aspect, and obey the laws of addiction (p. 691). His central thesis is that the human organism innately contrasts extreme affective experiences such as pain and pleasure. Simply put, the removal of one emotion often produces its opposite response-like the euphoria felt by the intact survivor of a near accident moments after recovering from the initial fright, or the rush the heroin addict feels after the painful injection of heroin. Similarly, skydivers, reflecting on their first skydiving experiences, often speak of the "incredible high" that follows each jump, while admitting their fear. "My feet didn't touch the ground for a week after my first jump!" (wf 35, 1,600 jumps, owner/operator). "It's such an incredible adrenalin rush" (wm 30, 216 jumps). "Scared the hell out of me" (wm 26, more than 1,400 jumps). "If anybody tells you they weren't scared the first times they jumped, they're either lying or crazy" (wf 25, three jumps).

Solomon proposes two other phenomena, habituation, or tolerance, and withdrawal syndromes on abstinence (p. 692). Through conditioning the individual becomes accustomed to the behavior and its expected rewards, while absence of the behavior is discomforting. Thus (in this view), like heroin addicts who grow to enjoy the actual act of self-injection (though initially unpleasant), skydivers grow to love leaping from planes because they learn to associate the subsequent thrill with the initially frightening act itself. In sum, they learn to love jumping and everything associated with it. Moreover, they crave skydiving when they are away from the sport. "It's like an addiction, I suffer withdrawal when I haven't jumped in a while" (wf 25,400 jumps). "I love it, man. I just can't get enough of it [free-fall]" (wm 40, 1,110 jumps, photographer). 
Thus, the opponent process model and related addiction models (Goode 1972, 1990; Mule 1981) predict that skydivers will become addicted to the high associated with the jump. These models also suggest that skydivers would seek increasing amounts of the agent (risk situations) producing the high as what was initially thrilling became the norm. As a result, skydivers would view risk as desirable rather than a thing to be minimized.

The addiction model is compelling. Skydivers, especially at the novice through intermediate levels, freely state that they are "addicted to the high," that they are "adrenalin junkies," that they "can't get enough," that they "lose interest in other activities and things," that their "relationships suffer," and that they "spend all of their money on skydiving." Moreover, a small percentage of skydivers graduate to BASE jumping, which is much riskier and even "more thrilling" than skydiving. "Everyday jumping was becoming boring, you . . . need to throw a little spice into it" (wm 44, 1,856 jumps, BASE jumper).

Thus, an addiction model does appear to explain part of the motivation for skydiving, particularly early involvement and, perhaps, the desire of some skydivers to BASE jump. However, it is a relatively simplistic and unidimensional hedonic view of risk. It does not explain or account for the complex set of behaviors and motives where skydivers set personal goals, work out performances, and otherwise cognitively develop their goals as skydivers. Thus, a more complex multidimensional perspective is required to explain the continuing involvement of most high-risk performers, one in which risk becomes a component in a play of reasoned action.

\section{How Do High-Risk Performers Perceive Risk?}

To understand high-risk performers' perceptions of risk, it is necessary to consider their higher-level motives, which evolve beyond thrill. While a thrilling context is desired, it must also provide the challenging and creative demands necessary to attain these additional motive outcomes. Specifically, the context must afford the participant some degree of creative control in order to attain mastery, self-efficacy, and flow. Because of this, high-risk participants tend to view risk multidimensionally, with three risk themes predominant: controllable versus uncontrollable risk, "edgework" and the illusion of control, and risk acculturation.

Controlled versus Uncontrolled Risk. High-risk performers seek controllable risk contexts where their abilities can be challenged. That is, they seek self-efficacy and authentication through controlled action, not random chance. Noncontrollable risk, or randomness, is avoided when possible. Particularly instructive of the insider's view of controllable versus uncontrollable risk is the response of Charles Houston, a famous mountain climber, when asked whether a particular route up a mountain was more attractive because of the number of lives that it had claimed (Klausner 1968).

Does the death of a climber make a certain mountain or
route more attractive than others? The answer is probably
yes, at least where the severity of the climb has been the
prime factor in the accident. It is not necessarily true,
however, where a fortuitous avalanche or sudden storm
has been the killer. The north face of the Eiger is often
tried despite its formidable death toll, because the acci-
dents have been due primarily to the climber's failure.
By contrast, the Marinelli Gully, whose avalanches have
killed many, does not have the same attraction. The
manageable risks that make a route difficult do attract
climbers, while the uncontrollable dangers do not. [P.
57]

The perceived ability to control unplanned as well as planned events is a key distinction between experienced and novice skydivers. Those who have successfully managed an unexpected event, such as a malfunctioning parachute, gain in status. They are perceived to be survivors, having faced and managed onrushing death. Novices, who have been trained to expect and to deal with emergency situations, but have yet to encounter one, often seek out these skydivers. Typically, a novice will ask, "Have you ever had a reserve ride?" (has the skydiver had to use his or her reserve parachute). Responding to this ritual question, the experienced skydiver relates his story, dutifully telling what it was like, what went through his mind, and what he learned. ${ }^{7}$ Status is accorded to these skydivers because they have proven that they are capable of controlling both the scripted and unscripted aspects of the context. Often, novices say that they "almost" wish that they would have their first reserve ride, not simply to get it over with, but so that they will know for sure whether they too can manage the situation. Of course, situations that are too easily mastered retain little interest to skydivers, and, like Houston's mountain climbers, many high-risk performers quickly learn to prefer contexts that test their abilities and sometimes the limits of their control.

Edgework and the Question of Illusion of Control. Many high-risk performers learn to like working at the edge of their abilities, "to push the envelope," so to speak, or, literally, as Chuck Yeager did when he flew his experimental jet through the "edge" of the earth's atmosphere to become unofficially the world's first astronaut (Wolfe 1979). Lyng (1990) refers to this as "edgework," or the personal exploration of the limits of both the context and the individual's ability to control it. Since both context and ability are perceived qualities,

\footnotetext{
${ }^{7}$ From the personal experience of the first author, who had his first reserve ride at about his 300 th jump, the confidence that comes from the knowledge that you function clearly under this life-threatening pressure reaffirms belief in self, one's training, and the equipment. It is a rite of passage.
} 
however, a question then arises as to the accuracy of those perceptions, especially when outcomes such as death and injury are considered.

From the perspective of a high-risk performer, virtually all feel that they are capable of managing the context in which they perform, with most leaving what to them is a comfortable margin between their risktaking behavior and the edge. Even those who operate on the extreme edge emphasize that they rarely go beyond the limits of their control, preferring to back down to jump or climb another day. For example, Reinhold Messner, who soloed Everest in 1980 without oxygen, has stated that he is extremely cautious and has often retreated from a difficult spot (Messner 1974). Similarly, John Bachar, a rock climber, who solos vertical rock faces (without equipment), and once within a 24-hour period soloed both Yosemite's El Capitan (3,500 feet) and Half Dome (2,200 feet), reflects: "Actually, I'm conservative. Yeah, chicken, I'm always operating way below my ability level. That's what I call the cushion. I hate feeling like I'm thrashing around up there. If I can't do it with control, I'll back off. In my own mind, I'm really a chicken"' (Boga 1988, p. 3). Scott Geil (wm 44), a BASE jumper who has parachuted from El Capitan, Half Dome, and skyscrapers in downtown Los Angeles, projects a similar caution and invariably speaks of the incredible care that precedes each BASE jump. "We all know what we're doing here is extremely dangerous even if everything goes perfectly. The preparation and planning is very detailed right down to escape routes and where we park the car" (65 BASE jumps, 1,856 skydives; Dead Horse, Alaska, 1991).

Still, these individuals freely state that the slightest mistake in their performance could be catastrophic. For instance, Geil explains that a BASE jumper, by virtue of the extremely low altitude of the jump, gives up the second chance that a reserve parachute affords typical skydivers. Moreover, the time factor is extremely compressed because of the low altitude; all actions must be calm, precise, timely, and correct. There is little margin for error. Similarly, Bachar, speaking of unprotected solo climbing, says simply, "If you fall, you die" (Boga 1988 , p. 7). While these particular high-risk athletes perform at the edge of what may be the limit of human ability, each feels that these risk contexts are within his control. Thus, the edge is relative to individuals' subjective perception of their ability and confidence level. The edge is fluid and represents a constantly changing limit of perceived abilities.

But is there an illusion of control (Langer 1975)? Do high-risk performers tend to overestimate their abilities to control risk? This is a difficult question. As Peter Hacket, the eleventh American to summit Mount Everest, said in reference to Messner's solo ascent of Mount Everest: "For Messner, it was a calculated risk [because of his high skill level]. On the other hand, Roger Marshall [also a highly skilled mountaineer], who tried it and died, probably thought the same thing"
(Boga 1988, p. 91). So did Scott Geil on his last BASE jump in November 1989, when swirling night winds caused his parachute to twist and to slam him into an adjacent skyscraper 450 feet above downtown Los Angeles. A miraculous combination of skill and luck saved him, although he was seriously injured. "It's hard to say how many times I've relived that moment. However, I knew that it could happen, and I did what I had to do. Now that I'm safe I see how I could have made it better, but I'm alive after an accident that's killed several people."

Lyng (1990) suggests that skydivers' calculations are subject to an illusion of control and cites related research on risk. Langer (1975), for example, shows that, as subjects in pure chance situations gain familiarity with the risk context and learn to develop coping strategies, their confidence in their ability to influence the outcome increases. Her subjects also incorrectly believed they had greater influence over lotteries when allowed to choose their own numbers. Given the apparent robustness of this phenomenon, and the fact that many experienced skydivers are injured or killed each year, an illusion-of-control explanation seems plausible.

However, we believe such a definitive conclusion would be misleading. Experienced skydivers have a fairly accurate idea of their ability levels and what is required on a particular jump. This is even more the case for extreme edgeworkers. High-risk performers are under no illusion regarding the risk of injury or death. For example, a highly experienced skydiver and former eight-way world champion stated at a seminar: "Don't kid yourselves. Skydiving is dangerous. I've had a lot of friends die skydiving. In reality, even though we maneuver through the sky, we are falling like a rock" (wm 32, 5,000 jumps; field notes, Zepherhills, Florida 1989). This suggests that Langer's examples of illusion of control do not necessarily apply to high-risk sports. It is one thing to risk overconfidence while making a $\$ 2$ lottery bet, where little is risked on the outcome, and quite another to trust your life to a potentially fatal and frightening behavior without carefully weighing the outcomes.

However, unscripted events do occur. Consider the swirling winds Scott Geil experienced, or the unseen wind turbulence at 60 feet that caused the first author's parachute to crash, resulting in 11 broken bones, or the avalanche that carried Reinhold Messner's brother to his death not more than 50 meters from Reinhold. In all three examples experienced individuals were injured or killed by essentially random events. Nevertheless, each performer understood the possibility of such an occurrence. Death or injury is part of the risk that participants knowingly take. What the outsider may fail to consider is that edgeworkers accept the potential for unexpected risk and, like experts in most fields, have developed sophisticated knowledge bases that relate specific contingencies to specific procedural responses. Thus, injuries, when they do occur, can be seen as the 
result of a calculated risk rather than an illusion of control.

If an illusion of control is operative, it is more likely to occur with skydivers of moderate experience than novice or highly experienced skydivers. For instance, novices and students jump initially on naive faith and trust in others and their equipment rather than on absolute belief in personal control. Rarely, if ever, are they permitted in contexts that test the limits of their abilities. In contrast, skydivers with moderate experience have earned their autonomy. Unlike the expert, however, the moderately experienced skydiver has not likely experienced, personally or vicariously, the full variance of external conditions and, hence, may be surprised by their severity. Thus, moderately experienced skydivers would appear to be most vulnerable to an illusion of control. As an experienced skydiver notes: "You get the 100-jump wonders, and they feel like they know everything, and that's sometimes the critical stage in jumping" (wf 34, 1,600 jumps). This possibility suggests a curvilinear relationship between the illusion of control and levels of high-risk experience with moderately experienced performers most susceptible to an illusion of control.

Risk Acculturation and Attribution of Causality. Clearly, participants must learn to accept risk. To become skydivers, however, they must not only accept risk, but become acculturated to it in order to attain motive outcomes related to efficacy and identity that require sustained calm and controlled action. Thus, the processes of motive evolution and risk acculturation are necessarily highly interrelated and occur simultaneously in reciprocating interaction. On one hand, risk acculturation is necessary in order to attain higher-level motives. On the other, it is the desire for these motive outcomes, which can only be acquired in the high-risk context, that drives the risk acculturation process. Thus, the development of a skydiving identity is a function of the motive evolution and risk acculturation process, which itself is a function of experience and socialization. This process begins immediately for novices as jump masters emphasize and associate the risks and rewards of skydiving. "People get killed skydiving, and if you don't pay attention it will bite you! This sport is not for everyone! However, if you do what you are supposed to do, you will be all right. There is nothing like this sport" (field notes, South Carolina, 1988). Thus, the initiate becomes aware of the key sociopsychological elements of skydiving. It is dangerous, but you can control it, especially if you listen and learn, and it is enticing that you are special and different if you do it.

Almost immediately, acculturation to the belief that skydiving risk is psychologically manageable begins. The initiate normatively hears and "parrots" from respected skydivers that "skydiving is probably safer than driving to the DZ." "I feel like I'm in more danger

\footnotetext{
${ }^{8}$ The first author personally has heard this identical rationale in rock climbing, scuba diving, hang gliding, and aerobatic contexts.
}

when I'm driving that truck every day. I don't feel that [skydiving] is that much of a risk" (wm 28,15 jumps).

The initiate is taught that the people who do get hurt do so because they failed to do what they were trained to do. Human error, or failure to manage the situation, causes death. Virtually any skydiver will tell you that 99 percent of the time it is people who fail, not their equipment. Thus, skydivers learn through training and successful experience to attribute causality to the skydiver, first and foremost. "Last year [1987] there were 23 [skydiving] deaths, and every one of them was the result of human error" (wf 30, 450 jumps).

Here, it might seem that skydivers are guilty of a fundamental error of attribution in which causality of negative outcomes is attributed to the person when it happens to others, but to external causes when it happens to oneself (Nisbett and Ross 1980). However, incident reports published in Parachutist magazine suggest otherwise and reinforce this acculturation of self-efficacy. Monthly, skydiving deaths (approximately two to three per month in 1989) and injuries, their probable causes, and procedures that could have averted them are reported. Rarely is a death or injury attributed completely to uncontrollable risk. Invariably, it is stated that human error contributed, even when the initial problem may have been externally caused.

Moreover, knowledge of these particular incidents also reinforces belief in the self, as high-risk performers typically feel that they would have been capable of handling the incident in question. Specifically, most experienced participants believe that their odds are better than average as they rule out whole categories of incidents that they feel wouldn't happen to them, because of their particular equipment, their reasonableness in planning, or their perceived ability. Thus, participants are gradually acculturated to believe in themselves, which is a key property of the high-risk identity. "I know something could happen, but I think that I have all the bases covered that I can cover" (wm 34, 1,038 jumps, pilot).

Thus, the development of a high-risk identity requires deviance neutralization (Goode 1990). In this transformation, a participant goes through a habituation period where the high-risk activity, once seen as "extraordinary" (deviant), gradually is perceived as the norm. This process produces a corresponding change in the individual's self-concept as well as a change in his or her interaction with outsiders. For example, during the early stages of this transformation, initiates become almost missionary in their zeal for the high-risk activity. This almost compulsive need to rationalize the high-risk behavior with outsiders is a reflection of internal processes counterbalancing a changing self-concept (Sykes and Matra 1957). As the high-risk identity develops, the participant gradually assumes the ideology of the subculture, which places the properties of the high-risk behavior clearly within the realm of the normal (Brannigan and McDougall 1983; Goode 1978). Hirschi 
(1969) writes that this process produces immunization (toward high-risk consumption in this case) through social bond as the novice evolves from outsider to insider.

Thus, with full acculturation the participant learns to manage the high-risk context and attains insider status, the risk experience becomes normalized, fear recedes, and s/he begins to view skydiving as a sport to be enjoyed like any other. It becomes the norm with the full assumption of a high-risk identity (van Gennep 1960). Risk and outcomes associated with it are accepted as due course and are overtly questioned only when injury or death interrupts the status quo. Finally, as the participant passes through this period of acculturation and evolves a stable high-risk identity ("I am a skydiver"), the need to share experiences and to rationalize to outsiders diminishes. "Yeah, you used to try to get all your friends to make a jump, let's go, let's go. . . . [now] I just don't talk about skydiving much anymore [to outsiders] unless somebody asks me. I don't know why that is either. . . . I guess it's not a hobby anymore, it's a way of life, so to speak (wm 26, more than 1,400 jumps).

And Sometimes a Way of Death. On a warm Saturday afternoon during data collection, a skydiver "went in" at the Southern Skies Parachute Center. He never activated his main parachute, and inexplicably only pulled his "cutaway" handle, an inappropriate action. Thus, he took no effective action to save his life. At the funeral the casket remained closed. The deceased had been a well-integrated member of this tight, relatively small skydiving center, hosting parties with his family and generally taking part in most activities. Moreover, both his son and daughter were popular and active skydivers. His death hit Southern Skies especially hard.

His funeral, in a neighboring state, was attended by many skydivers, friends, and relatives. At the funeral the skydivers shared the experience of loss, but the funeral was only a temporary (albeit important) interruption in the normal flow of skydiving experience. All skydivers accepted his death as a part of skydiving life. His son and daughter jumped again within three weeks, and virtually all skydivers shared the following beliefs: "I guess after a number of years' experience and seeing other friends die, you come to see it as a part of skydiving life, you accept it. You know it is going to happen. You hope it doesn't, especially to your friends, but it's going to happen. It's going to happen here again" (wm 34, 1,038 jumps).

Nevertheless, death does serve as an interrupt mechanism, as it causes participants to reflect and take stock: "It hit me pretty hard, and I sat back and asked myself whether this is really worth it, you know. But the next day, I went out to practice [team skydiving] and everything was fine" (wm 31, 1,700 jumps). "It makes you think a lot, it makes you think what did he experience, what would that feel like, you know. . . . I guess you have to try and determine what you think death is and whether or not it is that bad anyway. You know, death can only be as bad as you make it" (wm 25, 325 jumps).

His death, now part of the lore of Southern Skies, was commonly believed to be the result of human error. Inspection indicated that his equipment was operable. He had taken action by activating his cutaway, or release mechanism, but it had been the wrong action. Thus, the manner of his death was seen as an affirmation of skydiving beliefs by insiders. Almost all felt that this type of accident was not likely to happen to them, and that if one follows basic procedures and stays current, this outcome is avoidable. It is important that this death did not disconfirm outstanding beliefs. Thus, skydivers at Southern Skies, although saddened, perceived affirmation of their beliefs in this regrettable but avoidable death. " "That's what it was, it was human error, it was a mistake. I feel good about it [in that sense], because it was not equipment failure. What really would bother me, in any kind of fatality, is equipment failure" (wm 44, 1,800 jumps).

In contrast, outsiders perceived the death as confirmation that skydiving risk is unnecessary and uncontrollable. Outsiders who spoke with the DZ owners were astonished that they would continue the Southern Skies operation. How could they when someone had died? How could skydiving be worth this potential outcome? The difference, in this regard, between outsiders, who see skydiving as a risky activity, and insiders, who see skydiving as a way of life, is reflected in the following remarks: "I don't think there is a skydiver in this world that would say: 'If I go in, I want them to shut down the operation.' There is no way any of us would want that. They don't stop the Indy 500 car race if they have an accident. They clean it up, they continue the race" (wm 44, 1,800 jumps, owner/operator). "If you're driving down the road and you see a bad wreck, somebody is dead in there, you don't park your car and get outside and say 'I'm not driving my car anymore' and walk home for the rest of the night; you drive on-same thing with skydiving"' (wm 26, 1,400 jumps).

The bottom line, which will always differentiate insiders and outsiders, is the assumption of this risk, to which the insider is acculturated, and which, for the outsider, who does not understand the rewards, is painfully unnecessary. To skydivers, the deaths that do occur, although never minimized, are accepted as part of the skydiving way of life. To outsiders, each skydiving death is questionable. This difference is expressed by a skydiver who simply and eloquently captures the meaning of high-risk consumption: "We don't have a death wish, we have a life wish! A wish to live life to the fullest and if by chance we do die skydiving, then at least we died doing what we loved" (wm 27, 1,000 jumps).

\footnotetext{
${ }^{9}$ However, three potential initiates who witnessed the accident prior to making their first jump departed without jumping or returning.
} 


\section{DISCUSSION AND FUTURE RESEARCH DIRECTIONS}

We have presented an in-depth exploration of highrisk consumption with skydiving as the main empirical focus. Our key findings center on the development of the high-risk identity, which results from the reciprocating dynamics of the motive evolution and risk acculturation processes. These processes are interdependent, occur in unison, and result in (1) the normalization of risk associated with the high-risk behavior and (2) an escalating motivation toward the behavior. Together, these outcomes both enable and define the high-risk identity.

Importantly, our findings also demonstrate the need to examine constructs such as motivation and risk taking as dynamic processes, rather than as static or trait variables. Undoubtedly, such dynamic processes underlay the development of consumer behavior constructs such as intrinsic and felt involvement. Likewise, the importance of examining risk-taking behavior as a process of acquisition versus personality type is underscored. Perhaps of utmost importance, our findings emphasize the inherent danger of focusing research efforts on single and isolated constructs, rather than on the more holistic and likely interaction and interdependence between constructs.

On the basis of our results, we believe that our findings generalize to most high-risk activities. Future research, however, is needed to establish generalizability. Useful research could focus on identifying the key transition variables that might explicate the process dynamics of motive evolution, risk acculturation, and identity construction. Such research should be useful to understanding a variety of consumer involvement behaviors. Future research could also focus on a comparison of person/context differences. For instance, do the extremely varied physical and temporal contexts of scuba diving, high-altitude climbing, formula 1 racing, white-water kayaking, and skydiving produce identical, subtle, or perhaps highly varied experiences of flow, community, and identity construction? In addition, both traditional and comparative analyses could be used to examine specific propositions such as illusion of control and attribution bias across both respondents and risk activities.

To fully explore the boundary conditions and the robustness of our findings, a systematic analysis is needed that compares high-risk and less risky consumer behaviors. The key distinction between high-risk behavior and other, less risky consumer behaviors is that the overt possibility of death is recognized and accepted by the individual as a condition of action. This distinction cannot be overemphasized, as it likely produces qualitative differences in how individuals approach and assess risky behaviors, the intensity of outcomes, and the profoundness of personal change that results. Beyond this major and fundamental difference, however, a comparison of similarities and other distinctions between high-risk and less risky consumer behaviors should benefit our understanding of each.

The most obvious comparison is between high-risk activities and other sports, such as running, biking, and skiing. In many ways, the benefits attainable from highrisk activities are also obtainable from these less risky activities-flow, identity generation, mastery, and feelings of catharsis. As such, the benefits of less risky and high-risk activities may occupy a continuum varying only in degree. However, qualitative differences that result from high-risk acculturation preclude the total acceptance of a continuum theory. For example, context differences are a key distinguishing criterion. High-risk participants knowingly seek, prepare for, and perform in contexts containing both controllable and random risk. Rarely, however, does the average runner (or biker), even when pushing his or her limit, perform in a risk context that contains a high level of both expected and random risk. Thus, high-risk performers, unlike everyday runners, learn to be risk managers who seek and create edgelike risk contexts within which to act. Future research should focus on this critical risk distinction. Researchers could also further our understanding of identity construction and risk acculturation by examining the transition variables that motivate individuals to escalate from low- to higher-risk behaviors, such as when runners run ultramarathons across deserts, mountain bikers attempt steep and snow-covered terrain, and everyday skiers helicopter to extreme slopes.

A second area of comparison interest is between highrisk and compulsive/impulsive (CI) behaviors, as each involves repetitive behavior and has addictive qualities (Hartung and Farge 1981). However, the repetitive behavior associated with CI behaviors, unlike typical highrisk behavior, ultimately harms the individual and others psychologically and financially (O'Guinn and Faber 1989). Compulsive/impulsive behaviors, such as impulsive shopping, substance abuse, and gambling, are viewed as dysfunctional disorders. In contrast, high-risk consumption, which like any behavior can become dysfunctional, is not in itself a disorder. For example, high-risk, as compared to CI, behaviors are typically empowering instead of disempowering, self-efficacious instead of dysfunctional, and goal directed instead of impulsive (see Glasser 1976). As such, CI "addictions" involve a negative spiral of anxiety, ritual action, risk denial, and perceived loss of control (O'Guinn and Faber 1989), while motives for high-risk consumption describe a distinct spiral of risk acceptance, anxiety reduction, action, and a positive self-image. Future research could focus on the initial motives of $\mathrm{CI}$ and high-risk individuals and attempt to isolate the transition variables that lead to these respective dysfunctional and functional spirals of behavior.

A third area of comparison involves identity construction through high-risk consumption and consumer behaviors such as elective plastic surgery (Schouten 
1991). Through plastic surgery a relatively superficial physical change is undertaken by the individual in an attempt to achieve certain preexisting or fantasized blueprints for a "possible self" (Markus and Nurius 1986). However, unlike self-change via high-risk consumption, change through plastic surgery does not result from confronting and overcoming a challenging context or through increasing skill levels. Less a long-term transition, more a one-time event, it involves external change that the individual hopes will lead to internal change. In contrast, for high-risk performers, identity change occurs as an internalized process (see Maslow 1961; Zurcher 1977). Thus, while plastic surgery and high-risk consumption are both instrumental to selfchange, the former is largely superficial and externally driven. Future research should compare the level and endurance of self-change that results from both elective surgery (and perhaps nonsurgical means such as dieting) and high-risk consumption. This could be done through longitudinal studies and should provide insight into identity formation processes.

\section{CONCLUSION}

By means of our extended dramatic model, we have grounded high-risk consumption in everyday behavior. As such, skydiving, as our key high-risk exemplar, is seen as a dramatic, self-fulfilling behavior that occurs on a specified stage with carefully casted actors and coactors. The act is clearly defined, with the skydive planned and rehearsed. Agon is created as the skydiver as protagonist pits him- or herself against the worthy antagonism of the behavior, a test against nature and self. Tension, which is critical to the dramatic viewpoint, is carefully controlled by balancing actor and context in a well-thought-out script. Following the period of "conflict," denouement is attainable with its correspondent anguish or catharsis, depending on success or failure.

Within this framework, the individual experiences a highly interrelated pattern of motive evolution and risk normalization. Motives, initially normative and externally derived, evolve to motives of efficacy, identity formation, and transcendent experience. A related pattern of risk acculturation coincides which results in the normalization of the initially frightening behavior. The high-risk identity results from these dynamics.

Ultimately, high-risk activities provide individuals with an enabling context for performance on a stage carefully delimited to match their abilities and motives. Dramatic scenes can be readily scripted, which, when creatively enacted, provide catharsis and, above all, a sense of maximized potential and a life more richly experienced.

[Received November 1991. Revised August 1992.]

\section{REFERENCES}

Anderson, Laurel and Marsha Watkins (1991), "Japan-a Culture of Consumption," in Advances in Consumer Research, Vol. 18, ed. Rebecca H. Holman and Michael R. Solomon, Provo, UT: Association for Consumer Research, 129-134.

Bammel, Gene and Lei Lane Burris-Bammel (1982), Leisure and Human Behavior, Dubuque, IA: Brown.

Bandura, Albert (1982), "The Self and Mechanisms of Agency," in Psychological Perspectives on the Self, ed. Jerry Suls, Hillsdale, NJ: Erlbaum, 3-39.

Barnard, Jessie (1968), "The Eudaemonists," in Why Men Take Chances, ed. Samuel Z. Klausner, Garden City, NY: Doubleday.

Belk, Russell R. (1988), "Possessions and the Extended Self," Journal of Consumer Research, 15 (September), 139-168. , Melanie Wallendorf, and John F. Sherry, Jr. (1989), "The Sacred and Profane in Consumer Behavior: Theodicy on the Odyssey," Journal of Consumer Research, 16 (June), 1-38.

Blau, Theodore H. (1980), "The Lure of the Deep," in The Many Faces of Suicide, ed. Normal L. Farberow, New York: McGraw-Hill, 410-427.

Boga, Steve (1988), Risk! An Exploration into the Lives of Athletes on the Edge, Berkeley, CA: North Atlantic.

Brannigan, A. and A. A. McDougall (1983), "Peril and Pleasure in the Maintenance of High Risk Sport: A Study of Hang-Gliding," Journal of Sport Behavior, 6 (March), 37-51.

Brown, Ivor (1927), First Player, London: Gerald Howe.

Burke, Kenneth (1945), A Grammar of Motives, New York: Prentice-Hall.

(1968), "Dramatism," in International Encyclopedia of the Social Sciences, Vol. 7, ed. David L. Sills, New York: Macmillan, 445-452.

Campbell, Colin (1987), The Romantic Ethic and the Spirit of Modern Consumerism, New York: Blackwell.

Cantor, Nancy, Hazel Markus, Paula Niedenthal, and Paula Nurius (1986), "On Motivation and the Self-Concept," in Handbook of Motivation and Cognition, ed. Richard Sorrentino and E. Tory Higgins, New York: Guilford, 96-121.

Celsi, Richard L. (1989), "Jumping the Midnight Sun," Parachutist, 30 (December), 44. - (1992), "Transcendent Benefits of High-Risk Sports," in Advances in Consumer Research, Vol. 19, ed. John F. Sherry, Jr. and Brian Sternthal, Provo, UT: Association for Consumer Research, 636-641.

and Jerry C. Olson (1988), "The Role of Involvement in Attention and Comprehension Processes," Journal of Consumer Research, 15 (September), 210-224.

Cheney, Sheldon (1952), The Theater, London: Longmans, Green.

Collier, John, Jr. and Malcolm Collier (1987), Visual Anthropology: Photography as a Research Method, Albuquerque, NM: University of New Mexico Press.

Csikszentmihalyi, Mihaly (1974), Flow: Studies in Enjoyment, Public Health Service Grant Report No. R01HM 2288302 .

- (1975), Beyond Boredom and Anxiety, San Francisco: Jossey-Bass. 
and Isabella Selega Csikszentmihalyi (1988), Optimal Experience, Cambridge: Cambridge University Press.

Durkheim, Emile ([1848] 1951), Suicide: A Study in Sociology, New York: Free Press.

Edwards, Richard (1979), Contested Terrain: The Transformation of the Workplace in the Twentieth Century, New York: Basic.

Epstein, Seymour and Walter D. Fenz (1965), "Steepness of Approach and Avoidance Gradients in Humans as a Function of Experience: Theory and Experiment," Journal of Experimental Psychology, 70 (July), 1-12.

Fenz, Walter D. and Seymour Epstein (1967), "Gradients of Physiological Arousal in Parachutists as a Function of an Approaching Jump," Psychosomatic Medicine, 24 (January), 33-50.

Fishman, Joshua A. (1960), “A Systemization of the Whorfian Hypothesis," Behavioral Science, 5 (October), 323-339.

Glaser, Barney G. and Anselm L. Strauss (1967), The Discovery of Grounded Theory Strategies for Qualitative Research, Chicago: Aldine.

Glasser, William (1976), Positive Addictions, New York: Harper \& Row.

Goffman, Erving (1959), The Presentation of Self in Everyday Life, Garden City, NY: Doubleday Anchor.

(1967), "Where the Action Is," in Interaction Ritual, New York: Doubleday Anchor, 149-270.

Goode, Erich (1972), Drugs in American Society, New York: Knopf.

- (1978), Deviant Behavior: An Interactionist Approach, Englewood Cliffs, NJ: Prentice-Hall.

- (1990), Deviant Behavior, Englewood Cliffs, NJ: Prentice-Hall.

Grove, Stephen J. and Raymond P. Fisk (1983), "The Dramaturgy of Services Exchange: An Analytical Framework for Services Marketing," in Emerging Perspectives on Science Marketing, ed. Leonard L. Berry et al., Chicago: American Marketing Association, 45-49.

Gutman, Jonathan (1982), "A Means-End Chain Model Based on Consumer Categorization Processes," Journal of Marketing, 46 (Spring), 60-72.

Hall, Edward T. (1959), The Silent Language, Garden City, NY: Doubleday.

Hartung, G. Hartley and Emile J. Farge (1981), "Compulsive or Excess Sports," in Behavior in Excess: An Examination of Volitional Disorders, ed. S. Joseph Mule, New York: Free Press, 287-311.

Heimer, Carol A. (1988), "Social Structure, Psychology, and the Estimation of Risk," in Annual Review of Sociology, Vol. 14, ed. W. Richard Scott and Judith Blake, 491519.

Hill, Ronald Paul and Mark Stamey (1990), "The Homeless in America: An Examination of Possessions and Consumption Behaviors," Journal of Consumer Research, 17 (December), 303-321.

Hirschi, Travis (1969), Causes of Delinquency, Los Angeles: University of California Press.

Holbrook, Morris C. and Elizabeth C. Hirschman (1982), "The Experiential Aspects of Consumption: Consumer Fantasies, Feelings, and Fun," Journal of Consumer Research, 9 (September), 132-140.

Klausner, Samuel Z. (1968), Why Man Takes Chances: Studies in Stress-Seeking, Garden City, NY: Anchor.
Langer, Ellen J. (1975), "The Illusion of Control," Journal of Personality and Social Psychology, 32 (February), 311 328.

Lincoln, Yvonna S. and Egan G. Guba (1985), Naturalistic Inquiry, Beverly Hills, CA: Sage.

Lyng, Stephen G. (1990), "Edgework: A Social Psychological Analysis of Voluntary Risk Taking," American Journal of Sociology, 95 (January), 851-886.

and David A. Snow (1986), "Vocabularies of Motive and High Risk Behavior: The Case of Skydiving," in $A d-$ vances in Group Processes, Vol. 3, ed. Edward J. Lawler, Greenwich, CT: JAI.

Malinowski, Bronislaw (1923), "The Problem of Meaning in Primitive Languages," in The Meaning of Meaning, ed. Charles K. Ogden and Ibor Armstrong Richards, New York: Harcourt Brace.

Markus, Hazel and Paula Nurius (1986), "Possible Selves," American Psychologist, 41 (September), 954-969.

Marx, Karl ([1867] 1972), “Capital Selections," in The Marx Engels Reader, ed. Robert C. Tucker, New York: Norton.

Maslow, Abraham H. (1961), "Peak-Experiences as Acute Identity-Experiences," American Journal of Psychoanalysis, 21 (2), 254-260.

McLuhan, Marshall (1965), Understanding Media: The Extensions of Man, New York: McGraw-Hill.

Mead, George H. ([1934] 1950), Mind, Self, and Society, ed. Charles W. Morris, Chicago: University of Chicago Press.

Messner, Reinhold (1974), The Seventh Grade, New York: Oxford University Press.

Mick, David G. (1986), "Consumer Research and Semiotics: Exploring the Morphology of Signs, Symbols, and Significance," Journal of Consumer Research, 17 (September), 196-213.

Mills, C. Wright (1959), The Sociological Imagination, New York: Oxford University Press.

Mitchell, Richard G., Jr. (1983), Mountain Experience: The Psychology and Sociology of Adventure, Chicago: University of Chicago Press.

Mule, S. Joseph (1981), Behavior in Excess: An Examination of Volitional Disorders, New York: Free Press.

Myers, David G. and Helmut Lamm (1976), “Group Polarization Phenomenon," Psychological Bulletin, 83 (July), 602-627.

Nisbett, Robert and Lee Ross (1980), Human Inference: Strategies and Shortcomings of Social Judgment, Englewood Cliffs, NJ: Prentice-Hall.

O'Guinn, Thomas C. and Ronald J. Faber (1989), "Compulsive Buying: A Phenomenological Exploration," Journal of Consumer Research, 16 (September), 147-157.

Olson, Jerry C. and Thomas J. Reynolds (1983), "Understanding Consumers' Cognitive Structures: Implications for Advertising Strategy," in Advertising and Consumer Psychology, ed. Larry Percy and Arch Woodside, Lexington, MA: Lexington.

Propp, Vladimir I. (1958), Morphology of the Folktale, trans. Laurence Scott, ed. Svatava Pirkova-Jakobson, Bloomington: Indiana University Press.

Schouten, John W. (1991), "Selves in Transition: Symbolic Consumption in Personal Rites of Passage and Identity Reconstruction," Journal of Consumer Research, 17 (March), 412-425.

Sherry, John F., Jr. (1987), "Keeping the Monkeys Away from the Typewriters: An Anthropologist's View of the Con- 
sumer Behavior Odyssey," in Advances in Consumer Research, Vol. 14, ed. Melanie Wallendorf and Paul Anderson, Provo, UT: Association for Consumer Research, $370-373$.

(1990), "A Sociocultural Analysis of a Midwestern American Flea Market," Journal of Consumer Research, 17 (June), 13-30.

Short, James F., Jr. (1984), "The Social Fabric at Risk: Toward the Social Transformation of Risk Analysis," American Sociological Review, 49 (December), 711-725.

Simmel, Georg (1968), The Conflict in Modern Culture, and Other Essays, trans. K. Peter Etzkorn, New York: Teachers College Press.

Society of Actuaries (1983), Transactions: 1981 Reports of Mortality and Morbidity, Chicago: University of Chicago Press.

Solomon, Michael R. (1983), "The Role of Products as Social Stimuli: A Symbolic Interactionism Perspective," Journal of Consumer Research, 10 (December), 319-329.

Solomon, Richard L. (1980), "The Opponent Process Theory of Acquired Motivation: The Costs of Pleasure and the Benefits of Pain," American Psychologists, 35 (September), 691-712.

Sykes, Gresham M. and David Matra (1957), "Techniques of Neutralization: A Theory of Delinquency," American Sociological Review, 22 (December), 664-670.

Tolman, Edward C. (1932), Purposive Behavior in Animals and Men, New York: Academic Press.

Trope, Yaacov (1986), "Self-Enhancement and Self-Assessment in Achievement Behavior," in Handbook of Motivation and Cognition, ed. Richard Sorrentino and E. Tory Higgins, New York: Guilford Press, 350-378.
Turner, Ralph H. (1969), "The Theme of Contemporary Social Movements," British Journal of Sociology, 20 (December), 390-405.

(1972), "Passages, Margins, and Poverty: Religious Communitas," Worship, 46 (July), 390-412.

(1976), "The Real Self: From Institution to Impulse," American Journal of Sociology, 81 (March), 989-1016.

and Edith Turner (1978), Image and Pilgrimage in Christian Culture: Anthropological Perspectives, Oxford: Blackwell.

van Gennep, Arnould (1960), The Rites of Passage, trans. Monika B. Vizedom and Gabrielle L. Caffee, Chicago: University of Chicago Press.

Wallack, Michael A., Nathan Kogan, and Daryl J. Bem (1962), "Group Influence on Decision Making," Journal of Abnormal and Social Psychology, 65 (August), 75-86.

Wallendorf, Melanie and Russell W. Belk (1989), "Assessing Trustworthiness in Naturalistic Consumer Research," in Interpretive Consumer Research, ed. Elizabeth C. Hirschman, Provo, UT: Association for Consumer Research, 69-84.

Werner, Oswald and G. Mark Schoepfle (1987), Systematic Fieldwork, Vol. 2, Newbury Park, CA: Sage.

Whorf, Benjamin Lee (1940), "Science and Linguistics," Technological Review, 44, 229-231, 247-248.

Wolfe, Tom (1979), The Right Stuff, New York: Farrar, Straus \& Giroux.

Zuckerman, Marvin (1979), Sensation Seeking: Beyond the Optimal Level of Arousal, Hillsdale, NJ: Erlbaum.

Zurcher, Louis A. (1977), The Mutable Self: A Self-Concept for Social Change, Beverly Hills, CA: Sage. 